\title{
The November 1999 High Maturity Workshop
}

Mark C. Paulk

Mary Beth Chrissis

March 2000

SPECIAL REPORT

CMU/SEI-2000-SR-003 

CarnegieMellon

Software Engineering Institute

Pittsburgh, PA 15213-3890

\section{The November 1999 High Maturity Workshop}

CMU/SEI-2000-SR-003

Mark C. Paulk

Mary Beth Chrissis

March 2000

Software Engineering Process Management 
This report was prepared for the

SEI Joint Program Office

HQ ESC/DIB

5 Eglin Street

Hanscom AFB, MA 01731-2116

The ideas and findings in this report should not be construed as an official DoD position. It is published in the interest of scientific and technical information exchange.

FOR THE COMMANDER

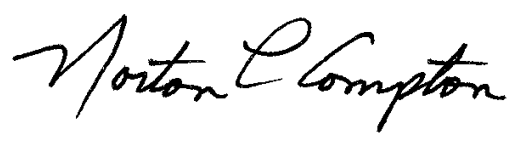

Norton L. Compton, Lt Col., USAF

SEI Joint Program Office

This work is sponsored by the U.S. Department of Defense. The Software Engineering Institute is a federally funded research and development center sponsored by the U.S. Department of Defense.

Copyright 2000 by Carnegie Mellon University.

NO WARRANTY

THIS CARNEGIE MELLON UNIVERSITY AND SOFTWARE ENGINEERING INSTITUTE MATERIAL IS FURNISHED ON AN "AS-IS" BASIS. CARNEGIE MELLON UNIVERSITY MAKES NO WARRANTIES OF ANY KIND, EITHER EXPRESSED OR IMPLIED, AS TO ANY MATTER INCLUDING, BUT NOT LIMITED TO, WARRANTY OF FITNESS FOR PURPOSE OR MERCHANTABILITY, EXCLUSIVITY, OR RESULTS OBTAINED FROM USE OF THE MATERIAL. CARNEGIE MELLON UNIVERSITY DOES NOT MAKE ANY WARRANTY OF ANY KIND WITH RESPECT TO FREEDOM FROM PATENT, TRADEMARK, OR COPYRIGHT INFRINGEMENT.

Use of any trademarks in this report is not intended in any way to infringe on the rights of the trademark holder.

Internal use. Permission to reproduce this document and to prepare derivative works from this document for internal use is granted, provided the copyright and "No Warranty" statements are included with all reproductions and derivative works.

External use. Requests for permission to reproduce this document or prepare derivative works of this document for external and commercial use should be addressed to the SEI Licensing Agent.

This work was created in the performance of Federal Government Contract Number F19628-95-C-0003 with Carnegie Mellon University for the operation of the Software Engineering Institute, a federally funded research and development center. The Government of the United States has a royalty-free government-purpose license to use, duplicate, or disclose the work, in whole or in part and in any manner, and to have or permit others to do so, for government purposes pursuant to the copyright license under the clause at 52.227-7013.

For information about purchasing paper copies of SEI reports, please visit the publications portion of our Web site (http://www.sei.cmu.edu/publications/pubweb.html). 


\section{Table of Contents}

1 The November 1999 High Maturity Workshop

2 Summaries from the Level 4 and 5 Organizations

2.1 AlliedSignal Defense \& Space Systems (now

Honeywell, Avionics Integration Systems)

Teterboro, NJ 3

2.2 BFL Software Limited, Bangalore, India 4

2.2.1 ROI and Improvement Trend Data 4

2.2.2 Unique or Distinguishing Practices 4

2.2.3 Issues in Achieving High Maturity 4

2.3 The Boeing Company, Space Transportation Systems, Kent, WA

2.4 Citicorp Information Technology Industries Limited (CITIL), Mumbai and Bangalore, India

2.4.1 ROI and Improvement Trend Data 5

2.4.2 Unique or Distinguishing Practices 6

2.4.3 Issues in Achieving High Maturity 6

2.5 HCL Perot Systems, Noida and Bangalore, India

2.5.1 ROI and Improvement Trend Data 7

2.5.2 Unique or Distinguishing Practices 7

2.5.3 Issues in Achieving High Maturity 8

2.6 IBM Global Services India, Bangalore, India 8

2.6.1 Unique or Distinguishing Practices 9

2.7 Litton Guidance and Control Systems, Woodland Hills, CA

2.8 Lockheed Martin Management \& Data Systems, King Of Prussia, PA 10

2.8.1 ROI and Improvement Trend Data 11

2.9 Lockheed Martin Mission Systems, Gaithersburg, MD 
2.10 Lockheed Martin Naval Electronics and

Surveillance Systems - Manassas, VA 11

2.10.1 ROI and Improvement Trend Data 13

2.10.2 Issues in Achieving High Maturity 13

2.11 Lockheed Martin Federal Systems, Owego, NY

2.11.1 ROI and Improvement Trend Data 14

2.11.2 Issues in Achieving High Maturity 14

2.12 Motorola, GSM (Global System for Mobile Communications) Systems Division, Network Systems Group, Arlington Heights, IL 15 2.12.1 Unique or Distinguishing Practices 15

2.12.2 Issues in Achieving High Maturity 15

2.13 Motorola India Electronics Ltd. (MIEL), Bangalore, India 15

2.14 NIIT Limited, New Delhi, India 16 2.14.1 Unique or Distinguishing Practices 16

2.14.2 ROI and Improvement Trend Data 16

2.15 Northrop Grumman, Air Combat Systems, Integrated Systems and Aeronautics Sector, El Segundo, CA

2.16 Oracle Software India Limited, India

Development Center, Bangalore, India 17

2.17 Raytheon C3I Fullerton Integrated Systems, Command and Control Systems/Middle East Operations, Fullerton, CA 18

2.18 Raytheon Missile Systems, Software Engineering Center, Tucson, AZ 18

2.18.1 ROI and Improvement Trend Data 19

2.18.2 Issues in Achieving High Maturity 20

2.19 Satyam Computer Services Ltd., India 20

2.19.1 ROI and Improvement Trend Data 21

2.19.2 Unique or Distinguishing Practices 21

2.19.3 Issues in Achieving High Maturity 22

2.20 United Space Alliance, Space Shuttle

Onboard Software Project, Houston, TX 22

2.20.1 Unique or Distinguishing Practices 23

2.20.2 Issues in Achieving High Maturity 23

2.21 Tata Elxsi Limited (TEL), Bangalore, India 24

2.21.1 Unique or Distinguishing Practices 24

2.21.2 ROI and Improvement Trend Data 25

2.21.3 Issues in Achieving High Maturity 25

2.21.4 ROI and Improvement Trend Data 25 
2.21.5 Issues in Achieving High Maturity 25

2.22 US Army, Communications and Electronics

Command (CECOM), Software Engineering

Center (SEC), Fire Support Software

Engineering, Fort Sill, OK 26

2.23 US Air Force, Directorate of Aircraft

Management, Software Division, Test Soft-

ware and Industrial Automation Branches

(OC-ALC/LAS), Tinker AFB, OK 26

2.23.1 ROI and Improvement Trend Data 27

2.23.2 Issues in Achieving High Maturity 28

2.24 Wipro GE Medical Systems,

Bangalore, India 28

2.24.1 ROI and Improvement Trend Data 29

2.24.2 Unique or Distinguishing Practices 29

2.24.3 Issues in Achieving High Maturity 29

2.25 Wipro Technologies, Global R \& D

Division, Bangalore, India 29

2.25.1 ROI and Improvement Trend Data 30

2.25.2 Unique or Distinguishing Practices 31

2.25.3 Issues in Achieving High Maturity 31

2.26 Wipro Technologies, Enterprise Solutions

Division (ESD), Bangalore, India 32

2.26.1 ROI and Improvement Trend Data 33

2.26.2 Unique or Distinguishing Practices 33

2.26.3 Issues in Achieving High Maturity 33

3 Preliminary Results of the 1999 High

Maturity Survey

4 Working Group Reports 37

4.1 Working Group 1: Statistics (Session A) 37

4.1.1 Observations 38

4.1.2 Recommendations for High Maturity Organizations $\quad 40$

4.1.3 Recommendations for the SEI 41

4.2 Working Group 1: Statistics (Session B) 42

4.2.1 What is Level 4 Really Trying to

Accomplish? 42

4.2.2 How Can You Better Prepare for Level 4? 43

4.2.3 Statistical Techniques $\quad 43$

4.3 Working Group 2: Assessments 44 
4.4 Working Group 3: CMM Integration 48

4.4.1 Impact of CMMI 49

4.4.2 Things to Worry about for Level 4 and 5 Organizations Adopting the CMMI

4.4.3 CMMI - Normative versus Informational Models 51

4.4.4 Continuous versus Staged 53

4.4.5 Statistical versus Quantitative 54

4.4.6 Theory versus. Practice 55

4.5 Working Group 4: Measurement

(Session A) 56

4.5.1 Linking Business Goals to Project

Goals and Measures 57

4.5.2 Similarities and Differences in People

Issues between Lower and Higher

Maturity Levels $\quad 58$

4.6 Working Group 4: Measurement

(Session B) 59

4.6.1 Observations 59

4.6.2 Data Quality and Cost of Data

Collection 59

4.6.3 Capability Baselines - Creation and Use $\quad 60$

4.6.4 Tying Software Quality to Business Objectives and Identifying the Relevant Process Measures $\quad 61$

4.6.5 Recommendations for High Maturity Organizations 61

4.6.6 Recommendations for the SEI 62

4.7 Working Group 5: Technology Transition 62

4.7.1 Goals of the Working Group: 62

4.7.2 Approach 63

4.7.3 INTRo as a Basis for Identifying Issues/Best Practices 63

4.7.4 Strategic Planning Insights 67

4.7.5 Strategic Planning Observations 67

4.7.6 TCM Improvements to SW-CMM v1.1 68

4.7.7 Best Practice Recommendations for Successfully Deploying Technologies 68

4.7.8 Recommendations for "TCM" 
Material Lower in SW-CMM 69

4.7.9 Summary 70

4.8 Working Group 6: Human Issues 70

4.8.1 Sustaining Enthusiasm after Hitting

Major Process Goals 71

4.8.2 Encouraging Workers to Report

Accurate Data 72

4.8.3 Resistance to Data Reporting: 73

4.8.4 Balancing Data Accuracy and Data Cost 74

4.8.5 Notes Regarding PSP

Implementation $\quad 74$

4.8.6 Avoiding or Managing Dysfunctional

Behavior Prompted by

Measurement

4.8.7 Tension Between More Process-

Oriented And Less Process-

Oriented Groups And Projects

4.8.8 Similarities and Differences in

People Issues between Lower and

Higher Maturity Levels

4.9 Working Group 8: Software Quality Assurance $\quad 78$

4.9.1 Discussion Framework 79

$\begin{array}{lll}4.9 .2 & \text { Observations } & 79\end{array}$

4.9.2.1 Independence to

Objectivity

4.9.2.2 Organizational

Resistance 81

4.9.2.3 Customer Integration 82

4.9.2.4 Push to Pull 83

4.9.2.5 Assurance Target 83

4.9.2.6 Skill Requirements $\quad 84$

4.9.2.7 Roles and Responsibilities 85

4.9.2.8 People Impact $\quad 86$

5 Considerations for Next Steps $\quad 87$

$\begin{array}{ll}\text { References } & 89\end{array}$

Appendix A: List of Workshop Participants 91 
Appendix B: List of High Maturity Organizations

Participating

Appendix C: SEI Strategy for Ensuring Valid

Implementation and Appraisal of Level 4

and 5 Process Areas: October 28, 199998

Introduction and Background 98

Purpose 99

Candidate Strategies for Addressing the Need 99

1. Internal SEI Actions 99

2. Define Improvements for Maturity

Level 4 and 5 Process Areas and

Appraisals of SW-CMM V1.1 and other CMMs. $\quad 100$

3. CMM Training and Education 100

4. Appraisal Method Training and Education $\quad 100$

5. Workshops 100

6. Conference and Journal Papers 100

7. Technical Reports and Publications 101

8. Informal Communications Between the SEI and the CMM Community 101 


\section{List of Figures}

Figure 1 Major Phases of INTRo Life Cycle

64

Figure 2 Strategic Planning/TCM Framework

Adapted from Litton-PRC 


\section{List of Tables}

Table 1: Wheeler's Proposed New SPC Terminology 38

Table 2: Critical Success Factor and Issues for Project Initiation 64

Table 3: Organizational Analysis 64

Table 4: Technology-Based Solution Definition 65

Table 5: Technology Selection 65

Table 6: Whole Product Definition/Development 65

Table 7: Breakthrough 66

Table 8: Rollout 66 


\section{Abstract}

A workshop for high maturity organizations was held on November 16-18, 1999, at the Software Engineering Institute (SEI) in Pittsburgh. The purpose of this workshop was to better understand practices that characterize Level 4 and 5 organizations. Topics of discussion included both practices described in the CMM (Capability Maturity Model) and other practices that have a significant impact in mature organizations. Two themes were anticipated to be important to the workshop participants: statistical process control for software and the reliability and credibility of Level 4 and 5 assessments. Additional topics were solicited from the participants on CMM integration, measurement, technology, human issues, and quality assurance. This report contains brief summaries of the high maturity organizations participating in the workshop and the various working group reports. 


\section{The November 1999 High Maturity Workshop}

A workshop for high maturity organizations was held on November 16-18, 1999, at the Software Engineering Institute (SEI) in Pittsburgh. The purpose of this workshop was to better understand practices that characterize Level 4 and 5 organizations. This workshop was by invitation only. The SEI invited representatives from all known Level 4 and 5 organizations, Lead Assessors who had reported assessing a Level 4 or 5 organization, and selected individuals doing Capability Maturity Model (CMM )-related high maturity work.

Topics of discussion included both practices described in the CMM and other practices that have a significant impact in mature organizations. A survey on high maturity practices was distributed in October 1999 to all known Level 4 and 5 organizations. Participants in the workshop were briefed on the preliminary results of that survey to inspire discussion within the working groups. For representatives from Level 4 and 5 organizations, filling out the survey was a prerequisite for attending the workshop.

Two themes were anticipated to be important to the workshop participants: statistical process control for software and the reliability and credibility of Level 4 and 5 assessments. Additional topics were solicited from the participants prior to the workshop and used to drive the creation of working groups.

The workshop opened with brief presentations by the Level 4 and 5 organizations. Representatives from 26 high maturity organizations participated and are listed in Appendix B. A summary of their presentations is provided in Section 2 of this report. The organizational summaries were followed by the preliminary results of a survey on high maturity practices, briefly discussed in Section 3. The workshop participants then broke into working groups, and their discussions are summarized in Section 4.

Capability Maturity Model and CMM are registered in the U.S. Patent and Trademark Office. 


\section{Summaries from the Level 4 and 5 Organizations}

Representatives from Level 4 or 5 organizations were asked to make a brief ten-minute presentation about their organization. Information requested included

- the organization name and location

- a point of contact for the organization

- date(s) assessed at what maturity level(s)

- Lead Assessor(s)

- $\quad$ size of organization (number of software professionals)

- typical range of program size (e.g., 50-200 per thousand source lines of code [KSLOC])

- primary application domain(s)/ product line(s)

- return-on-investment and improvement trend data

- issues in achieving Level 4 or 5

- unique (distinguishing) practices, etc., that might contribute to the workshop discussions Summaries supplied by the organizations are provided in this section.

\subsection{AlliedSignal Defense \& Space Systems (now Honeywell, Avionics Integration Systems) Teterboro, NJ}

Maturity Level
Date of Assessment
Lead Assessor
Point of Contact
Web Page
Size of the Organization
Typical Program Size
Primary Application Domain

4

November 1996

Larry Bramble

Steve Janiszewski, stephen.janiszewski@honeywell.com

Ellen George, ellen.george@honeywell.com

www.6sigmasw.com

40 software engineers

$20 \mathrm{~K}$ to $200 \mathrm{~K}$ LOC

Avionics, vehicle management systems, and auto test systems

Honeywell AIS is a $100 \% \mathrm{PSP} / \mathrm{TSP}$ trained and operating organization. 


\subsection{BFL Software Limited, Bangalore, India}

\author{
Maturity Level \\ Date of Assessment \\ Lead Assessor \\ Point of Contact \\ Web Page \\ Size of the Organization \\ Typical Program Size \\ Primary Application Domain
}

\author{
4 \\ June 1999 \\ Carolyn Swanson \\ Ms. Sujatha Balakrishnan \\ General Manager (Quality and Training) \\ sujatha.ravi@bflsoftware.com \\ www.bflsoftware.com http://www.bflsoftware.com/ \\ 1000 plus as of December 23, 1999 \\ Medium sized projects \\ Development of systems software, applications software, ERP, product \\ development in areas of health care and hospital management
}

\subsubsection{ROI and Improvement Trend Data}

Cost of Quality at BFL is calculated by measuring appraisal cost and prevention cost. We are continuously on the sustaining pitch and slowly moving towards the optimizing level.

\subsubsection{Unique or Distinguishing Practices}

Business goals and Quality goals are tightly coupled. Training/orientation to all employees on new/enhanced processes is made mandatory. Process evolution on down-to-up approach through SEPG members from various technical teams across Business Units. Process and Project management tools customized depending on technology and complexity of the project to enhance productivity and reduce cycle time of development. Sharing of best practices across the organization through a central repository of project data. Disseminating knowledge across the organization through SEPG, Metrics Council and Tools Technology and Transition Group. SQA for every project to ensure process compliance at project level and organizational level. Quantifiable quality goals for each project and phase-wise analysis to adopt corrective measures to achieve the defined goals.

\subsubsection{Issues in Achieving High Maturity}

Convergence of various tools for process automation, usage of statistical data for process improvements and decision making. Changes in technology, non-availability of information on application of quantitative process management to software business realities. No clarity/guidelines available on sampling for assessment for an organization spread across different geographical locations and executing projects on various domain and technology areas. 


\title{
2.3 The Boeing Company, Space Transportation Systems, Kent, WA
}

\author{
Maturity Level 5 \\ Date of Assessment July 1996 \\ Lead Assessor Steve Masters \\ Mark Paulk \\ John $\mathrm{Vu}$ \\ Point of Contact $\quad$ Chuck Martin, Charles.Martin3@PSS.boeing.com \\ Gary Wigle, gary.b.wigle@boeing.com \\ Greg Fulton, gregory.p.fulton@boeing.com
}

\subsection{Citicorp Information Technology Industries Limited (CITIL), Mumbai and Bangalore, India}

Maturity Level
Date of Assessment
Lead Assessor
Point of Contact
Web Page
Size of the Organization
Typical Program Size
Primary Application Domain

5

October 1999

Ken Dymond

S. Santhanakrishnan

Anand Kumar

Anand Kumar

Head - SEPG

Anand.Kumar@citicorp.com

www.citil.com

1000

$50-1000$

Banking products and services - retail, corporate, investment, data warehouse, internet

The CITIL development centers in Mumbai and Bangalore were assessed at Level 4 through two backto-back CBA IPI assessments in December 1995. The Lead Assessors were Cynthia Wise and Ken Dymond. A part of CITIL, the Data Warehouse Center of Excellence, was assessed at Level 5 in a CBA IPI assessment in October 1999. The Lead Assessors in this assessment were Ken Dymond, S. Santhanakrishnan, and Anand Kumar.

\subsubsection{ROI and Improvement Trend Data}

Mean annual growth in productivity of 10 per cent

Mean annual reduction in defect density of 20 per cent

Percentage rework effort halved in four years 
Price of non-conformance down by 33 per cent in 4 years

ROI of $100 \%$ in the first year; $300 \%$ in the fifth year

\subsubsection{Unique or Distinguishing Practices}

Managing continuous inflow of requirements

Interim release cycle as low as four to six weeks

Evolutionary lifecycles piloted, evaluated, and found effective

Centralized-cum-dispersed SEPG responsibilities

Planned reuse of design and code components across the organization

Software rating using an empirical model

Intranet as the primary communication vehicle for process improvement activities and results

e.g., process changes, process pilots, Process Change Control Board

Technology evaluation and pilot

Defect prevention

High level of automation of software engineering and management activities

End-to-end automation for data capture

\subsubsection{Issues in Achieving High Maturity}

Non-repetitive nature and scope of work coming from hundreds of customers

High growth rate

A large inflow of new practitioners

Reducing life spans for methodologies and technologies

Business pressures to improve further even before the full benefits of current process improvement initiatives have accrued 


\subsection{HCL Perot Systems, Noida and Bangalore, India}

Maturity Level
Date of Assessment
Lead Assessor
Point of Contact
Web Page
Size of the Organization
Typical Program Size
Primary Application Domain

5

February 2000

Pradeep Udhas

Rakesh Soni, rakesh.soni@hpsglobal.com

www.hclperot.com

925

0.5 Million - 5 Million LOC

Development

Migration and re-engineering,-e-commerce and Web development

HCL Perot Systems (HPS) is a joint venture between Perot Systems and HCL Technologies with offices in USA, Europe, Asia Pacific and India. The venture was set up to strengthen Perot Systems Europe \& US software delivery capability and a channel to market in Asia Pacific region.

Enterprise-wide ISO 9001 certification: March 1998

Enterprise-wide CMM Level 4 assessment: July 1999

Enterprise-wide CMM Level 5 assessment: February 2000

Future Plans: People CMM assessment during 2001

\subsubsection{ROI and Improvement Trend Data}

HPS closely monitors the costs related to the quality initiative. It has achieved ROI of $400 \%$ on the investments made during the last 3 years. This covers only the tangible benefits like improved productivity, lower rework efforts and bonus received for meeting the quality criteria specified by the customers.

Defect density has shown improvement ranging from 5\% to $30 \%$ across various lines of business. Productivity has shown improvements ranging from $6 \%$ to $80 \%$.

\subsubsection{Unique or Distinguishing Practices}

Commitment by senior management is demonstrated by a monthly review by a steering committee headed by the CEO.

Independent customer satisfaction surveys are performed by the SEPG. These surveys, which have provided useful inputs for process improvement, have shown continuously improving trends. 
There is organization-wide participation of all employees in process improvement activities. Rewards and recognition are provided for best suggestions.

There is mandatory Quality Management System (QMS) training at the time of induction. Retraining is provided whenever major changes are carried out to the processes.

Flexibility of the QMS and extensive tailoring guidelines support adaptation to changing technologies.

Best practices are shared across the organization.

A dedicated competency development center focuses on training and continuously enhancing the skills of the employees.

Monthly internal audits are performed.

There are well-defined processes for support groups.

\title{
2.5.3 Issues in Achieving High Maturity
}

Issues in achieving high maturity include:

- high growth rates

- $\quad$ varying nature of projects

- reduced cycle time for Web based projects

\subsection{IBM Global Services India, Bangalore, India}

\author{
Maturity Level 5 \\ Date of Assessment Nov 1999 \\ Lead Assessor Richard Storch \\ Point of Contact A Asha Goyal, gasha@in.ibm.com \\ Maya Srihari, smaya@in.ibm.com \\ Size of the Organization Over 1700 software developers \\ Primary Application Domain Software Development, Conversion / Porting, Re-engineering, Testing, \\ Maintenance, Product Development
}

ISO 9001 accredited, March 1995

SEI CMM Level 4, achieved in November 1997

SEI CMM Level 5, achieved in November 1999 


\subsubsection{Unique or Distinguishing Practices}

"Learnings" (what went wrong, what went well) and project assets are systematically gleaned from projects, categorized for easy access and made available to all project managers who are facilitated during Project Initiation and Look-ahead meetings to avoid/assimilate practices.

Tools developed for internal use in projects are evaluated for propagation or enhancement in the organization by forming focus groups.

The GQM methodology is used to set meaningful goals and use appropriate measures to track them for different types of projects.

- Very detailed and simply explained metrics guidelines are made available to all practitioners. Performance metrics are widely communicated and best practices recognized. Metrics experts are available for consultation. Statistical analysis is done on defects and schedule commitments to study trends and common causes of variation.

Optimal Automation and access to all to process engineering activities via

- process change request and its management

- $\quad$ process release management

- process document access and navigation

Traceability is maintained for every process change with its incorporation in standard processes and release for use. It is valued based on a defined mechanism and awards given for Best Change suggestion.

High focus on customer satisfaction is achieved through

- periodic Customer Satisfaction Survey, analysis of results and process improvements to enhance services

- analysis of unsolicited customer feedback for process improvements

Business Effectiveness Surveys are conducted to ascertain employee satisfaction /morale and to take appropriate actions for improvement.

Quality group conducts SQA effectiveness surveys on QA group interaction with projects, technology usage surveys and process effectiveness surveys to get feedback from practitioners. Learnings database is continuously enhanced. New process assets are created for reuse.

One of the major strengths of the organization is the Individual Skill Development Program. This is created by individuals in consultation with their managers and tracked at the organization level along with training, and supported by extensive global training opportunities. 
All non-conformances and weaknesses are studied for the root causes; specific instances are taken up for organization level defect prevention by training, asset creation or management focus.

Defect prevention training on root cause analysis, look-ahead meetings and planning guidelines on triggers etc., are provided.

Technology changes are proactively taken up and processes for communication, piloting, rollouts, feedback, transitioning and sharing of experiences are well defined and supported by full time resources. Up-to-date technology for day-to-day activities is available to all practitioners. Access to worldwide intranet provides vast information on all topics in addition to access to Internet.

Organization-wide involvement and commitment to quality is visible in terms of management participation, resources availability and rewards, and a focus on all aspects of internal and external customer satisfaction.

\subsection{Litton Guidance and Control Systems, Woodland Hills, CA}

Maturity Level
Date of Assessment
Lead Assessor
Point of Contact
Size of the Organization
Typical Program Size
Primary Application Domain

4

December 1998

Mark Amaya

Ray Madachy, madachyr@littongcs.com

Approximately 125 software professionals

$20-350$ KSLOC

Integrated systems, inertial systems, displays and controls, IFF, fiber optics and acoustic sensors

\subsection{Lockheed Martin Management \& Data Systems, King Of Prussia, PA}

\author{
Maturity Level \\ Date of Assessment \\ Lead Assessor \\ Point of Contact \\ Web Page \\ Size of the Organization
}

4

November 1998

Andy Felschow

Carol Granger-Parker

Dennis Ring

M. Lynn Penn, mary.lynn.penn@lmco.com

Must enter through LMCO.COM then go to M\&DS

about 4500 
Typical Program Size

Primary Application Domain
500 KSLOC

Information Systems

\title{
2.8.1 ROI and Improvement Trend Data
}

Defect detection has moved significantly into earlier phases of the life cycle. Reduction of defects went from 14 per KSLOC to 10 per KSLOC (over three years).

Expanded SEPG to Process Board (cross functional and cross product lines) - found too much integration of processes not getting visibility if focused only on software processes.

\subsection{Lockheed Martin Mission Systems, Gaithersburg, MD}

Maturity Level

Date of Assessment

Lead Assessor

Point of Contact

Size of the Organization

Typical Program Size
5

October 1999

Paul Byrnes

Paul Weiler, paul.weiler@1mco.com

Al Aldrich, al.aldrich@1mco.com

LM-MS has over 50 programs with approximately 3000 people involved in software development and maintenance.

Program team size ranges up to 300 people, with program software size up to $5000 \mathrm{~K}$ source lines of code.

LM-MS conducted a combined assessment using two different models, the Capability Maturity Model (CMM) for Software, Version 1.1, and the EIA/IS 731.1 Systems Engineering Capability Model (SECM).

\subsection{Lockheed Martin Naval Electronics and Surveillance Systems - Manassas, VA}

\author{
Maturity Level \\ 5 \\ Date of Assessment \\ February 1999 \\ Lead Assessor \\ Judah Mogilensky \\ John Travalent \\ Donald White \\ Point of Contact \\ Donald G. White \\ Member, Integrated Process Group
}


donald.g.white@lmco.com

Typical Program Size

Primary Application Domain
$35 \mathrm{~K}$ to $1500 \mathrm{~K}$ Equivalent Source Statements

Embedded, real-time development of submarine systems

Lockheed Martin (LM) Naval Electronics and Surveillance Systems (NESS) - Manassas organization was assessed at Capability Maturity Model (CMM) Maturity Level 5 (Optimizing) in February, 1999. This achievement was the culmination of over 20 years of continuous (software) process improvement initiatives. The assessment used the latest CBA IPI methodology and was led by Judah Mogilensky of Process Improvement Partners, Inc. The assessment team consisted of two other SEI authorized Lead Assessors, John Travalent and Donald White.

LM NESS-Manassas is organized by business area and/or program. There are approximately 240 software engineering professionals, not including software quality engineers or software configuration management personnel. The software domain for LM NESS-Manassas is embedded, real-time development of submarine systems. These applications include: sonar systems and trainers, combat systems and trainers, navigation and trainers, and acoustic surveillance. LM NESS-Manassas has developed and delivered over 18 million source statements within the last 20 years. Program sizes typically range from 35,000 to 1,500,000 Equivalent Source Statements (ESS). ${ }^{1}$

LM NESS-Manassas has been doing process improvement activities for many years. Faganlike Peer Reviews were first introduced in the software engineering discipline in the late 1970s and extended to the system engineering discipline in the mid-1980s. The first process group was formed and began documenting an organization level process in the late 1980s. LM NESS-Manassas had its first assessment (using the Software Process Assessment methodology), in September 1990. This assessment resulted in a Maturity Level 3 rating. Since that time, many other process improvements have been incorporated into the organization level process and periodic reassessments have validated the increased maturity of the organization. $^{2}$ Additionally, several Software Capability Evaluation $\left(\mathrm{SCE}^{\mathrm{SM}}\right)$ appraisals have occurred, but with no indication as to the maturity level received.

\footnotetext{
${ }^{1}$ The Equivalent Source Statement (ESS) is used to estimate labor requirements. A normalized number reduces different source statement (SS) types to the effort that would be required in terms of newly developed SS. The default coefficients can be changed based on program considerations (e.g., COTS coefficient can - and should - be made non-zero if non-trivial effort is involved in its incorporation, such as customizing, configuring, etc.)
}

2 October, 1992

June, 1995

February, 1999
SPA Methodology
CBA IPI Methodology
CBA IPI Methodology
Level 3

Level 4

Level 5 


\subsubsection{ROI and Improvement Trend Data}

LM NESS-Manassas has continually monitored important factors that indicate the success or failure of the process improvement activities. One of these indicators is delivered product quality. For most LM NESS-Manassas customers, this translates into defects-per-delivered source statements. (Other factors such as cost and schedule performance are also monitored.) Since the inception of continual process improvement, the defect density (defects / million delivered source statements) has dropped several orders of magnitude while continuing to deliver the product on time and within budget.

\subsubsection{Issues in Achieving High Maturity}

One of the biggest obstacles LM NESS-Manassas faced in its journey to Levels 4 and 5 was being able to understand, educate, and institutionalize the difference between "mature" management based on measurements and Quantitative Process Management. However, many other practices that have been in place for quite some time have served LM NESS-Manassas well. Examples of these practices are

- use of Latent Defect model(s)

- use of software engineers in Software Quality Assurance (SQA) roles

- $\quad$ augmenting the CMM with ISO 9001

- SQA audits driven by ISO elements and CMM key process areas

- pre-tailoring of the organization's standard software process (OSSP) based on the type or size of the program

\subsection{Lockheed Martin Federal Systems, Owego, NY}

$\begin{array}{ll}\begin{array}{l}\text { Maturity Level } \\ \text { Date of Assessment }\end{array} & 5 \\ \text { Lead Assessor } & \text { December 1997 } \\ \text { Point of Contact } & \text { John Travalent } \\ & \text { Warren A. Schwomeyer } \\ & \text { Senior Quality Engineer } \\ & \text { warren.schwomeyer@lmco.com } \\ \text { Size of the Organization } & 560 \\ \text { Typical Program Size } & \text { 1K to 300K source lines of code } \\ \text { Primary Application Domain } & \text { Avionics, postal, and commercial }\end{array}$

Lockheed Martin Federal Systems (LMFS) - Owego was assessed at Level 5 of the Capability Maturity Model for Software (CMM) in December 1997. This achievement marked a significant milestone in the organization's long history of continuous quality improvement. This discussion will address the software organization and its demographics, the software 
process improvement history of the organization, and the challenges we see ahead of us for continuous software process improvement.

There are approximately 560 software professionals at the site. The primary application domains are Avionics (including mission, sim/stim, diagnostic and real-time embedded systems), Postal (including optical character recognition and material handling) and commercial (including infrastructure modernization and medical). Our programs range in size from $1 \mathrm{~K}$ to $300 \mathrm{~K}$ source lines of code with some outliers outside both ends of this spectrum.

LMFS - Owego's software process journey started in the late 1970's. Process development and improvement continued through the 1980s. We were assessed at Level 2 (and well on the way to Level 3) in 1991 using the Software Process Assessment (SPA) methodology. From 1992 through the present we have had almost annual Software Capability Evaluations performed by our customers as an acquisition activity. Each of these was performed to CMM Level 3 and the organization satisfied all levels. In 1996 the organization was assessed at CMM Level 3 using the CMM Based Appraisal for Internal Process Improvement (CBA/IPI) method. Half of the goals at both Levels 4 and 5 were satisfied indicating the process was Level 5 capable, but needing a longer period of performance to demonstrate institutionalization. In 1997, the organization achieved CMM Level 5 using the CBA/IPI method (Lead Assessor: John Travalent).

\subsubsection{ROI and Improvement Trend Data}

The two key measures of process performance have increased through this period of improvement. Productivity (delivered source lines of code per labor month) has increased an average of $11.1 \%$ per year since 1982 . Post-delivery defect rate (software defects per million delivered source lines of code) has improved an average of $11.7 \%$ per year since 1992 . During this period and while improving these performance measures, the organization's customer set transitioned from more than $90 \%$ Department of Defense (DoD) to a balance of DoD, Postal and commercial.

\subsubsection{Issues in Achieving High Maturity}

Some of the challenges which lie ahead include the application of the process set across an ever-widening spectrum of program types (DoD and commercial) and sizes. Commercial off-the-shelf (COTS) programs also present unique challenges in applying the process set. Another challenge before us is the development of Statistical Process Control methods and tools to bring this tool out of the hands of the statisticians for use by the practitioners.

LMFS-Owego embraces the CMM principles and practices beyond the software processes by embedding them in our Integrated Systems Development (ISD) process and applying them to our process management as well as program management. LMFS-Owego is looking ahead to maturing the System Engineering processes and CMMI. 


\subsection{Motorola, GSM (Global System for Mobile Communications) Systems Division, Network Systems Group, Arlington Heights, IL}

Maturity Level

Date of Assessment

Point of Contact

Size of the Organization

Primary Application Domain
5

October 1997

Barbara Hirsh, hirsh@cig.mot.com

250 in 1997

Cellular infrastructure

\subsubsection{Unique or Distinguishing Practices}

Orthogonal Defect Classification

Statistical correlation of customer satisfaction scores to internal metrics

QPM training

\subsubsection{Issues in Achieving High Maturity}

Rapid growth

\subsection{Motorola India Electronics Ltd. (MIEL), Bangalore, India}

\author{
Maturity Level \\ Date of Assessment \\ Lead Assessor \\ Point of Contact
}

\author{
5 \\ November 1993 \\ John Pellegrin \\ Sarala Ravishankar, sarala@miel.mot.com
}




\subsection{NIIT Limited, New Delhi, India}

\author{
Maturity Level \\ Date of Assessment \\ Lead Assessor \\ Point of Contact \\ Web Page \\ Size of the Organization
}

Typical Program Size

Primary Application Domain
5

September 1999

Richard Storch

Bhaskar Chavali, BhaskarC@NIIT.com

www.niit.com

NIIT has 3800 employees across all business groups. At the time of the CMM assessment in Sept 1999, the software group had 450 in New Delhi, 250 in other metros, 300 abroad

3000 FPs (1000 - 15000 FPs)

e-commerce, Web applications, client/server applications, reengineering, migration/conversion, maintenance

ISO certifications and CMM assessments:

- First ISO 9001 certification from BVQI, UK in 1994

- $\quad$ ISO 9001 recertification from BVQI, UK in 1997

- Assessed at SEI CMM Level 3 in July 1997

- Assessed at SEI CMM Level 5 in Sept 1999

\subsubsection{Unique or Distinguishing Practices}

NIIT has implemented Crosby's Complete Quality Management System (CCQMS), propounded by the quality guru Philip Crosby. The Quality Education System (QES) is based on Crosby's four absolutes of quality. Training for QES is provided to all employees as part of the organization induction program. The premise of the Personal Quality Initiative (PQI) is that if each individual improves in personal and professional areas due to their own personal quality initiatives, then the organization benefits in the long term. This methodology enables each NIIT employee to improve his / her personal quality by providing the opportunity, methodology and the tools. All NIIT employees have been trained to use PQI.

NIIT has a dedicated process group and TQM group to facilitate the maintenance and creation of the software development and maintenance processes. Almost all the functional organizations, such as Financial Service Organization (FSO), Internal Communication Organization (ICO), Commercial Services Organization (CSO), Human Resource Organization (HRO), etc., within NIIT are ISO certified.

\subsubsection{ROI and Improvement Trend Data}

From April 1998 to September 1999:

- $14 \%$ improvement in productivity

- $33 \%$ reduction in effort overrun 
- $31 \%$ reduction in schedule slippage

- $36 \%$ reduction in (rework/total effort) ratio

- $20 \%$ decrease in PONC/person (Price Of Non Conformance)

Productivity Index of 27 in September 1999 (calculated through SLIM).

\subsection{Northrop Grumman, Air Combat Systems, Integrated Systems and Aeronautics Sector, EI Segundo, CA}

$\begin{array}{ll}\begin{array}{l}\text { Maturity Level } \\ \text { Date of Assessment }\end{array} & 4 \\ \text { Lead Assessor } & \text { Oct 1998 } \\ \text { Point of Contact } & \text { Don Dortenzo } \\ \text { Size of the Organization } & \begin{array}{l}\text { Leitha Purcell, purcele@mail.northgrum.com } \\ \text { Approximately 350 software } \\ \text { professionals at time of assessment. }\end{array} \\ \text { Typical Program Size } & \text { 40KSLOC to 1MSLOC } \\ & \text { 10 to over 200 software engineers } \\ \text { Primary Application Domain } & \text { Avionics systems, ground support } \\ & \text { systems, weapon systems }\end{array}$

\subsection{Oracle Software India Limited, India Development Center, Bangalore, India}

$\begin{array}{ll}\text { Maturity Level } & 4 \\ \text { Date of Assessment } & \text { May } 1999 \\ \text { Lead Assessor } & \text { Pradeep Udhas } \\ \text { Point of Contact } & \text { Ashish Saigal, asaigal@in.oracle.com }\end{array}$




\subsection{Raytheon C3I Fullerton Integrated Systems, Command and Control Systems/Middle East Operations, Fullerton, CA}

Maturity Level

Date of Assessment

Lead Assessors

Points of Contact

Size of the Organization

Typical Program Size

Primary Application Domain
5

Oct 1998

Paul Byrnes

Jane Moon

Ronald Ulrich

Ivan Flinn

Bruce Duncil

Janet Bratton

Jim Hudec

Jane A. Moon, jmoon@west.raytheon.com

Janet Bratton, jabratton@west.raytheon.com

Approximately 1400 people, including 400 software engineers, 450 systems and hardware engineers, and 150 support staff. Approximately 360 software engineers in 1998 at time of assessment.

60-220 software engineers

0.75-2 millions lines of developed source code

40-200 embedded COTS software products

Command, control, and information systems

International air traffic control systems

Traffic management systems

\subsection{Raytheon Missile Systems, Software Engineering Center, Tucson, AZ}

Maturity Level

Date of Assessment

Lead Assessor

Point of Contact

Size of the Organization

Typical Program Size

Primary Application Domain
4

October 1998

John Ryskowski

Michael D. Scott

Department Manager

mscott1@west.raytheon.com

Approximately 800 software professionals

There were 250 in Oct 1998

Team sizes range from 2 to 30

KSLOCs from $10 \mathrm{~K}$ to $250 \mathrm{~K}$

Missile systems 
The Software organization at Raytheon Missile Systems, in Tucson, was assessed at CMM Level 4 in October of 1998. This achievement marked a significant milestone in the organization's quest for continued process maturity and improvement. This discussion will address the software organization and its demographics, the process improvement history of the organization, our return on investment, and the issues we continue to face as we move strive to move forward.

The engineering directorate in Tucson is organized by function or discipline. There are approximately 800 software professionals, which include software quality engineers and software configuration management personnel. This compares to just 250 in October of 1998, over 300 percent increase in just over a year. This growth has been a significant factor in our ability to maintain our process improvement momentum, as will be discussed later. The software domain for Tucson is embedded real-time development of missile systems and support software. Our team sizes range from 2 to 30 with program sizes from $10 \mathrm{~K}$ to $250 \mathrm{~K}$ source lines of code.

Although the Missile Systems organization had been doing process improvement activities for many years it was not until the early 90's that our activities began to focus around the Capability Maturity Model. In 1994 we baselined our process capability using the results of a Software Capability Evaluation done as an acquisition activity and internal evaluations. We estimated our capability at CMM Level 2. A detailed software process improvement plan was developed and implemented over the following two years, and in 1996 the organization was assessed at CMM Level 3 using the CBA IPI method. Based on the findings of the 1996 assessment and the organization's goals, a new software process improvement plan was developed, and in 1998 the organization achieved CMM Level 4 (again under the CBA IPI method - Lead assessor: John Ryskowski). Our future goals are to achieve Level 5 in 2001.

\subsubsection{ROI and Improvement Trend Data}

A key factor in our success has been the ability to show that our efforts have had value to the overall organization. We continue to look at our return on investment to make sure that we are truly making the progress we expect. Our latest data includes the investments made from 1994 through 1998, looking at software quality (reduction of rework costs through defect containment), productivity (lines of code per hour improvement), and customer satisfaction (program capture rate). Costs incurred included both organizational costs as well as program costs for process and process improvement activities. We acknowledge that this is not a true experiment and that there are many other factors that come in to play (e.g., better tools, more experienced workforce, etc.), but we do believe that our process activities have been key to our 6:1 return on investment over this four-year period. 


\subsubsection{Issues in Achieving High Maturity}

We still have a long way to go to achieve our ultimate goal of continuous process improvement as a way of life in the organization. Significant issues continue to place challenges in our path. In the last year Raytheon has consolidated all of its missile business to Tucson which has more than tripled the number of programs and personnel in the organization. With this growth has been a significant influx of new engineers. We continually have to "sell" process and process improvement to program management ("Why do we need to be higher than Level 3?"). And finally, there continues to be issues regarding process funding, especially with other disciplines getting on board (a good thing, but spreads available funding thin).

Tucson has made great progress over the past six years and we expect to continue. We are well on our way to Level 5 and are keeping our eye on the next challenge of CMMI.

\subsection{Satyam Computer Services Ltd., India}

Maturity Level
Date of Assessment
Lead Assessor
Point of Contact
Web Page
Size of the Organization
Typical Program Size
Primary Application Domain

\author{
Level 5 in for all Indian locations \\ March 1999 \\ Richard Knudson \\ Prabhuu Sinha,prabhuu@satyam.com \\ www.satyam.com \\ 4000 total employees, 3300 software professionals \\ 10-100 KSLOC
}

Satyam is a complete IT solutions provider.

Satyam was ISO/TickIT certified in March 1995, and re-certified in September 1998.

The nature of projects done at Satyam include

- maintenance

- new development

- conversion

- migration

The types of projects are mainly

- monolithic information systems

- two-tier client-server software

- three-tier client-server software

- systems software 
- embedded software

- commercial software packages

\subsubsection{ROI and Improvement Trend Data}

Improvements observed in past one year

Development Projects

- $40 \%$ Reduction in Effort Estimation Variance

- $24 \%$ Reduction in Schedule Estimation Variance

- $8 \%$ Reduction in Delivered Defect Density

Maintenance Projects

- $\quad 53 \%$ Reduction in Effort Estimation Variance

- $34 \%$ Reduction in Schedule Estimation Variance

- 50 \% Reduction in Delivered Defect Density

\subsubsection{Unique or Distinguishing Practices}

Satyam uses an enterprise tool for monitoring

- Implementation of CMM

- Implementation of QMS

Satyam uses a tool for providing organization-wide access to

- quality system

- process training

- project knowledge base

- process suggestions box

All business units and support units in Satyam operate on a Profit Center approach with an internal customer-supplier relationship. All support units also have defined processes. Every business unit / support unit reviews its quality issues every month. SQA conducts regular project process monitoring to provide continuous process implementation support to projects. Projects conduct regular project introspective / retrospective meetings to share the learning 
from the project with other Project Leaders. The Satyam Learning Center facilitates the building up of individual and organizational skills and competencies.

Satyam has dedicated support units for building competencies on

- tools and technologies

- business domains

\subsubsection{Issues in Achieving High Maturity}

Quantifying the impact of varying project attributes on productivity and quality

Satyam, being an IT solutions provider, conducts different types of projects for different customers. Examples of varying project attributes are environment details (Platform, language, etc.), project specific attributes (Project Size, complexity, domain, etc.), project team skills and customer specific attributes (how they present requirements and changes, their own process maturity and appreciation, culture, language, schedules imposed by them).

Organization level productivity and quality baselines are difficult to set since there are very few similar projects. The impact is both in terms of normalization at organization level and goal setting at project level.

In-process (mid-term) corrective actions (QPM) in short duration projects (three to four months) are not very effective. They are also not easy to implement due to high schedule pressure. Goal setting for new technology projects by piloting is difficult because the pilot projects in Satyam are very small in size and may not give feasible data. Defect prevention learning in early life-cycle phases often cannot be used within the same project. It is used in other projects via sharing. Due to these factors, the project does not see the immediate benefit of causal analysis and DP meetings.

\subsection{United Space Alliance, Space Shuttle Onboard Software Project, Houston, TX}

Maturity Level
Date of Assessment
Lead Assessor
Point of Contact
Web Page
Size of the Organization
Typical Program Size
Primary Application Domain

\section{5}

Nov 1989

Donald Sova

Julie R. Barnard, julie.r.barnard@usahq.unitedspacealliance.com www.unitedspacealliance.com

250

400K lines of avionics software, 1.3M lines of application software Space Shuttle software 
The Space Shuttle Onboard Software project is a part of the United Space Alliance Corporation based in Houston, Texas. The project was previously operated by IBM, Loral, and Lockheed Martin before joining United Space Alliance on July 4, 1998. The project (under IBM at the time) was assessed at CMM Level 5 in November of 1989 by an SEI-trained NASA team, led by Donald Sova of NASA Headquarters Code Q.

The Space Shuttle's flight software (Primary Avionics Software System, PASS) is responsible for the guidance, navigation, and flight control functions performed during all phases of the Shuttle flight. The flight software consists of over 400,000 lines of code that run on the Shuttle's onboard computers. To satisfy NASA's requirement for software that meets the highest safety and reliability standards, the PASS flight software project evolved a software process that yields a highly predictable quality result. By executing the process faithfully to specified process standards, the flight software produced by the process is predictably near zero defects.

The project also develops and maintains over 1.3 million lines of Flight Software Application Tools that support configuration management, software builds, test and simulation, automatic verification, and software reconfiguration. The rigorous processes applied to these tools have yielded exceptional product quality levels as well.

The project size is generally around 250 people. The project resides currently within a larger software organization of approximately 600 people, which includes a major subcontractor assessed at CMM Level 5 in October 1999.

\subsubsection{Unique or Distinguishing Practices}

Some of the distinguishing practices the project is recognized for include

- rigorous application of formal inspections, including software requirements inspections

- in-depth defect prevention process, including the detailed examination of every software defect from a process escape perspective

- matrixed program management and control board structure

- long-term continuous process improvement

\subsubsection{Issues in Achieving High Maturity}

One of the challenges facing the project over the year period since its CMM Level 5 assessment has been to sustain its practices across the company changes and reorganizations. By leaving intact the organization structure, core management, and process infrastructure, the best practices continued successfully across the corporate boundaries. 
Future activities include transferring best practices to other parts of the company. The recently established corporate software process owner and corporate SEPG would be the primary mechanism for advancing the software process maturity of the overall company software process.

\subsection{Tata Elxsi Limited (TEL), Bangalore, India}

Maturity Level
Date of Assessment
Lead Assessor
Point of Contact
Web Page
Size of the Organization
Typical Program Size
Primary Application Domain

4

August 1999

Pradeep Udhas

M Thangarajan

Corporate Manager - Quality and Training

$\underline{\text { mtr@teil.soft.net }}$

www.tataelxsi.com

300

$5 \mathrm{~K}$ to $150 \mathrm{~K}$ source lines of code

Networking protocol development (TCP/IP, ATM, ISDN, SNMP, BGP, etc)

System development (embedded systems, ASIC design, VHDL and Verilog modeling, firmware including DSP)

Visual computing (2D/3D graphics, animation, data visualization, etc)

Internet $\&$ intranet group (Web enabling of products).

The Design \& Development Center of Tata Elxsi Limited, in Bangalore, was assessed at CMM Level 4 in August of 1999. This achievement marked a significant milestone in the organization's quest for continued process maturity and improvement.

The Quality Management System of our organization was first designed to meet the ISO 9001, Tick It guidelines, and we obtained the certification in February 1997. Subsequently our processes were greatly enhanced to meet the requirements of the Capability Maturity Model, and the necessary implementations were carried out over the next two years. On August 13, 1999, the organization was assessed at Level 4 using the CBA-IPI method. The assessment was conducted by KPMG (Lead Assessor: Mr. Pradeep Udhas).

\subsubsection{Unique or Distinguishing Practices}

The Quality Management System (QMS) is available to all employees through the Intranet. Past data from projects, best practices and inputs on the customer are shared across the organization through the "process database" on the Intranet. Organization baselines are established in line with the organization's quality policy. Each project sets tailored quality objectives based on the organization baselines and stage-wise analysis is done to arrive at corrective actions if the objectives are not met. Statistical Process Control Methods like control charts, Rayleigh curves, and Gompertz curves are used widely across projects to measure the effectiveness of verification and validation activities. A process improvement plan is de- 
veloped and this forms the basis for our process improvement activities. The SEPG and the SQA group are responsible for process improvement initiatives and ensure information is disseminated across the organization. Our future goal is to achieve Level 5 in year 2000.

\subsubsection{ROI and Improvement Trend Data}

A key factor in our success has been the ability to show that our efforts have had value to the overall organization. As a result of widespread use of data, our estimation accuracy has improved from $25 \%$ to $12 \%$, our outgoing defect density has reduced from 3 defects/KLOC to 0.75 defects/KLOC, and there has been a $25 \%$ improvement in effort overrun from what it was three years ago.

\subsubsection{Issues in Achieving High Maturity}

We still have a long way to go to achieve our ultimate goal of continuous process improvement as a way of life in the organization. Significant issues continue to place challenges in our path. These include:

- Managing growth due to high infusion of new recruits.

- New customers with unknown process maturity levels.

- Knowledge management.

- Better alignment of business goals to process strategies in a proactive fashion.

We have made great progress over the last three years and we expect to continue.

\subsubsection{ROI and Improvement Trend Data}

A key factor in our success has been the ability to show that our efforts have had value to the overall organization. We are able to deliver more than $75 \%$ of our projects in time with high degree of customer satisfaction resulting from very low outgoing defects.

\subsubsection{Issues in Achieving High Maturity}

We still have a long way to go to achieve our ultimate goal of continuous process improvement as a way of life in the organization. Significant issues continue to place challenges in our path. These include

- managing growth due to high infusion of new recruits

- new customers with unknown process maturity levels

- knowledge management

- better alignment of business goals to process strategies in a proactive fashion

We have made great progress over the last three years and we expect to continue. 


\title{
2.22 US Army, Communications and Electronics Command (CECOM), Software Engineering Center (SEC), Fire Support Software Engineering, Fort Sill, OK
}

\author{
Maturity Level \\ 4 \\ Date of Assessment \\ Nov 1997 \\ Lead Assessor \\ Don Couch \\ David Zubrow \\ Wolf Goethart \\ Point of Contact \\ Don Couch, couchdc@fssec.army.mil \\ Phil Sperling, sperlips@fssec.army.mil \\ Size of the Organization \\ 340 \\ Typical Program Size \\ $20 \mathrm{~K}-1000 \mathrm{~K}$ SLOC \\ Primary Application Domain \\ Field artillery, message processing, communications, operating sys- \\ tems

\subsection{US Air Force, Directorate of Aircraft Management, Software Division, Test Software and Industrial Automation Branches (OC-ALC/LAS), Tinker AFB, OK}

Maturity Level
Date of Assessment
Lead Assessor
Point of Contact
Size of the Organization
Typical Program Size
Primary Application Domain

\author{
4 \\ Nov 1996 \\ Judah Mogilensky \\ Kelley Butler \\ Management and Technical Support Branch Chief \\ OC-ALC/LASM \\ kelley.butler@tinker.af.mil \\ 350 \\ $5 \mathrm{~K}$ to $100 \mathrm{~K}$ source lines of code \\ Avionics test software development and maintenance
}

The Test Software and Industrial Automation Branches at the Oklahoma City Air Logistics Center, Tinker AFB, Oklahoma, were assessed at CMM Level 4 in November 1996. This achievement, the first Level 4 in Federal service, was significant in the organization's quest for continued process maturity and improvement. We have furthered strengthened our im- 
provement efforts with ISO 9001 Registration in November 1998. These efforts were further validated in May 1999 when the organization was awarded the IEEE Award for Software Process Achievement, only the fifth organization to receive the award in the five years it has been in existence. This discussion will address the software organization, its demographics, the organization's process improvement history, return on investment, and the issues we face as we strive to move forward.

The Test Software and Industrial Automation Branches' primary workload is avionics test software development and maintenance (94\%). Other functions include automatic test system development, jet engine testing, jet engine trending, non-destructive inspection, and support of the jet engine overhaul process. There are approximately 350 software professionals. This compares to just 90 in 1990, an almost 400 percent increase in the past nine years. Our process improvement successes along with our improvements in productivity and defects have directly resulted in our growth. Our team sizes range from 3 to 60 with test program sizes from $5 \mathrm{~K}$ to $100 \mathrm{~K}$ source lines of code. It should be noted that our projects consist of multiple test programs, ranging from one to more than one hundred.

The Test Software and Industrial Automation Branches have focused on Software CMMbased improvement since 1990 when our first SEI-based assessment was performed. In March 1993, one month after the release of Software CMM v.1.1, the first CMM based assessment was performed by the SEI at our site, resulting in a Level 2 rating. Judah Mogilensky led our 1996 Level 4 assessment where two of the three Level 5 KPAs were also deemed satisfied. The only KPA we did not satisfy, Defect Prevention, has been strengthened by our implementation of ISO 9001, including the Corrective and Preventive Action clause. We were registered to ISO 9001/TickIT in November 1998.

A key factor in our success has consistent and active leadership. With the exception of a leadership change in one branch and the addition of two branches due to growth, our senior organizational leadership has not changed since 1990. We have also maintained a consistent focus on our customers and on implementing improvements that truly benefit the organization.

\subsubsection{ROI and Improvement Trend Data}

We continue to refine and examine our return on investment to make sure that we are truly making the progress we expect. Additionally, "stretch" productivity goals are set each year for our branches. Our latest data shows our software quality (reduction of defects) and productivity (man-hours and months per Test Program Set).

Defects per KSLOC

- Average 3.3 in early $1990 \mathrm{~s}$

- Average 0.4 in mid 1990s 
- $\quad$ Latest Data showing 0.06 defects per KSLOC (1998 TPSs)

TPS Development Productivity

- $1600 \mathrm{Mhrs} / 13$ Months per TPS - 1993

- $1200 \mathrm{Mhrs} / 12$ Months per TPS - 1996

- $1150 \mathrm{Mhrs} / 12$ Months per TPS - 1997

- $923 \mathrm{Mhrs} / 12$ Months per TPS - 1998

- $1081 \mathrm{Mhrs} / 18$ Months per TPS - 1999

*B-2 Program, Contractual Obligations increased man-hours and decreased cycle time

\subsubsection{Issues in Achieving High Maturity}

We feel that, while our improvement efforts have been very successful, we now have to place additional emphasis on sustaining and continuing our efforts - continuous and incremental improvement. This is an area that is directly benefited by our ISO 9001 efforts and the required third-party audits. One area that we feel that we excel in is a highly disciplined maintenance process which closely mirrors our development process and gives our customers confidence in the changes that we are making to their mission critical software.

Our biggest Maturity Level 4/5 issue is determining the proper application of SPC for Software. Recent focus has been on the application of SPC for Project Management as well as the proper use of cost and schedule reserve. Additional focus has also been placed on proper accounting of requirement changes and re-planning efforts. We are working to use SPC in a manner that benefits the organization and adds value to our process.

\subsection{Wipro GE Medical Systems, Bangalore, India}

$\begin{array}{ll}\begin{array}{l}\text { Maturity Level } \\ \text { Date of Assessment }\end{array} & 5 \\ \text { Lead Assessor } & \text { Jan } 1999 \\ & \text { Richard Knudson } \\ & \text { Rama Rao } \\ \text { Point of Contact } & \text { K.V. Ramaswami } \\ & \text { Six Sigma Master Black Belt } \\ & \text { kv.ramaswami@geind.ge.com } \\ & \text { http://www.wipro-ge.com/ } \\ \text { Web Page } & \text { Software: 170, Total: 650 } \\ \text { Size of the Organization } & \text { Medical scanners }\end{array}$




\subsubsection{ROI and Improvement Trend Data}

\begin{tabular}{|l|r|r|r|}
\hline & $\mathbf{1 9 9 7}$ & $\mathbf{1 9 9 8}$ & $\mathbf{1 9 9 9}$ \\
\hline Effort Overruns (Actual/Estimated) & & & \\
\hline Mean & $135 \%$ & $105 \%$ & $98 \%$ \\
\hline Std. Deviation & $56 \%$ & $12 \%$ & $11 \%$ \\
\hline \%Projects with > 10\% overrun & $70 \%$ & $5 \%$ & $0 \%$ \\
\hline & & & \\
\hline Schedule Overruns (Actual/Estimated) & & & \\
\hline Mean & $142 \%$ & $113 \%$ & $100 \%$ \\
\hline Std. Deviation & $84 \%$ & $30 \%$ & $7 \%$ \\
\hline \%Projects with > 10\% overrun & $70 \%$ & $30 \%$ & $0 \%$ \\
\hline & & & 5.2 \\
\hline $\begin{array}{l}\text { Quality in Sigma Terms (from Defects / Million } \\
\text { Test Cases) }\end{array}$ & 3.3 & 4.5 & $1 \%$ \\
\hline Rework Effort \% of total project & $12 \%$ & $3 \%$ & \\
\hline
\end{tabular}

\subsubsection{Unique or Distinguishing Practices}

Six Sigma for process and product quality (through design) improvement

One-to-one mapping of quality models to business models

\subsubsection{Issues in Achieving High Maturity}

Creating one look and feel for user

Integrating ISO and EN46001

FDA/QSR 2.0 and Six Sigma methods

\subsection{Wipro Technologies, Global R \& D Division, Bangalore, India}

$\begin{array}{ll}\text { Maturity Level } & 5 \\ \text { Date of Assessment } & \text { June } 1999 \\ \text { Lead Assessor } & \text { Richard Knudson } \\ & \text { Mark Paulk } \\ \text { Point of Contact } & \text { V. Subramanyam } \\ & \text { Technical Manager (Process and Quality) } \\ & \text { Subramanyam.venkat@wipro.com }\end{array}$




\author{
Web Page \\ Size of the Organization \\ Typical Program Size
}

Primary Application Domain www.wipro.com

Over 2000 software professionals

Small and medium sized (10 - 100 KSLOC) with maximum up to 500 KSLOC

System software, communications and networking (datacom and telecom) and embedded systems and IP enablers. Design solutions for VLSI/ASIC , H/W circuits as well as system integration support

WIPRO Technologies, Global R \& D Division is a part of WIPRO Corporation, the largest publicly traded company in India.

Global R \& D Division offers design service to the large global platform and equipment vendors for the Internet infrastructure. This is done by deriving expertise from over 2000 engineers in the areas of Platform Technologies, Communication and Networking Technologies, Embedded Systems Technologies and VLSI / System Design.

Global R \& D's Quality journey started in 1992 with a formal ISO 9001 initiative. The division was certified for ISO 9001 in Sept 1994. Soon after that, the division continued further process improvement initiatives based on the SEI CMM model. Global R \&D was assessed at SEI CMM Level 4 on March 1997 and at SEI CMM Level 5 in June 1999. Focus during the Quality journey is to plan and implement process improvement activities based on business need, to meet customer requirements and to overcome the current pain areas facing the project teams.

\subsubsection{ROI and Improvement Trend Data}

Some of the benefits realized from the process improvement program are

- continuous improvement trend in customer satisfaction level as reflected by periodic customer satisfaction survey results.

- control of project schedule and effort overruns. Less than $10 \%$ of projects had schedule overrun and less than $15 \%$ of projects had effort overrun during the year 98-99.

- reduced detection of acceptance defect over the years after the release of work products to the customer

- high level of in-process defect removal efficiency of over $95 \%$ from past three years and $98 \%$ during the year 98-99

- formal reviews institutionalized and considered as strength of the organization and helping the project teams in catching around $85 \%$ of defects within the phase

- widening the scope of business in different geographies and in new areas of domains 


\subsubsection{Unique or Distinguishing Practices}

Some of the best practices institutionalized during the quality journey are

- a single integrated documented web based quality system and process assets accessible to all employees on the intranet

- $\quad$ systematic collection and analysis of metrics data at project level and well defined DP activities like Look Ahead Meetings and root cause analysis

- implementation of role called Quality Improvement facilitators for process facilitation and process consultancy to project teams

- project Managers owning the responsibility of project level QA activities

- rigorous audit mechanism with focus areas defined for each audit. Supplemented by periodic CMM based process assessments

- use of Query based tool called HPD (Historical Project Database) to query past projects data on various parameters for better estimation and for planning defect prevention activities

- dedicated tools group working on development and implementation of process automation tools to automate software engineering practices of the division

- use of web based in-house tools for capturing effort ETS ( Effort Tracking system), Review defects ARTS (Automatic Review tracking system) and DeLTA (Defect Logging and tracking system) etc.,

- use of Six Sigma methodology for improving selected business critical transactional processes

\subsubsection{Issues in Achieving High Maturity}

Working with customers of different process maturity

Need to continuously train practitioners due to high growth rate

Non repetitive projects in diverse business domains

Deriving benefits of metrics analysis for short duration projects 


\title{
2.26 Wipro Technologies, Enterprise Solutions Division (ESD), Bangalore, India
}

\author{
Maturity Level 5 \\ Date of Assessment December 1998 \\ Lead Assessor Richard Storch \\ Point of Contact Subbarao TV \\ GM-QA \\ subbarao.tangirala@wipro.com \\ Web Page \\ www.wipro.com \\ Size of the Organization \\ 4000 software professionals \\ Typical Program Size \\ Primary Application Domain \\ medium sized (50 - $75 \mathrm{KSLOC)}$ with maximum up to $1000 \mathrm{KSLOC}$ \\ e-commerce, Enterprise application, data warehousing, infrastructure \\ management, client server, legacy maintenance, system software, em- \\ bedded systems, telecom
}

Wipro Technologies, ESD is a part of WIPRO, a global provider for software and services to Fortune 500 companies. It is the largest publicly traded company of India.

Wipro ESD was assessed at SEI CMM Level 5 on Dec 1998, based on CBA IPI method. The Lead Assessor was Richard F. Storch. A well defined framework for analysis, approval and implementation of process improvement proposals from all employees, ISO audits, internal assessments, continuous improvement councils, top management review and Six Sigma teams form the cornerstone for continuous improvement

4000-plus highly skilled software professionals form the backbone of the organization. Main service offerings are in e-commerce, Enterprise application, data warehousing, infrastructure management, client server, legacy maintenance, system software, embedded systems and telecom. The industry segment focus is in finance, retail, utility, healthcare, corporate, and telecom. The typical program size are medium sized (50 - 75 KSLOC) with maximum up to 1000 KSLOC. Total number of projects being executed at geographically distributed development center is approximately 200.

The foundation for quality improvement journey was established in 1992 by an ISO 9000 initiative to formulate disciplined processes for conducting software operations. Having achieved ISO 9001 Tick IT standard in 1995, we selected the SEI CMM model to improve process maturity further. The first milestone was reaching SEI CMM Level 3 in Jun 1997. Process improvement journey continued and we reached SEI CMM Level 5 maturity in Dec 1998. Process improvement continues by all employees taking part in the journey, with additional focus by leveraging on Six Sigma methodologies. Six Sigma approach focuses on defect reduction and cycle time reduction by enforcing data centered approach, customer focus and measuring financial benefit from process improvement effort. The Six Sigma milestone is to reach 4-sigma by March 2000 and 6 sigma by Dec 2002 in all the critical business processes. 


\subsubsection{ROI and Improvement Trend Data}

Some of the benefits realized from the process improvement program are

- measured and predictive processes with clearly defined metrics for Effort overrun, Schedule overrun, Rejection index, productivity indices, Customer satisfaction index etc.

- well defined defect prevention at project level involving defect reporting, root cause analysis, preventive action plan, implementation and prevention feedback

- control of project schedule overruns. Almost $70 \%$ of 56 projects in 98-99 were completed within or on time

- improved estimation capability due to increased use of metrics. There has been marked decline in effort overruns. Statistics shows a decline from $20 \%$ in 1996 to $6 \%$ in 1998.

- reduced defects and minimization of rejections due to increase process focus at every stage has resulted in increased productivity . It has been observed that around $79 \%$ of the 92 projects completed in 1998 had a defect ratio of below 1 error/ KSLOC

- reduced risk due to institutionalization of formal risk management procedures for risk identification, assessment and control.

\subsubsection{Unique or Distinguishing Practices}

Some of the practices which is helpful in our quality journey are

- web based quality system accessible by all employees across geographical locations with additional features for initiation of process improvement proposals, review by domain experts and consolidation by SEPG.

- web based tool for the conduct of company wide ISO audits

- automation tools for project status reporting at different levels

- tools for resource (hardware, software and human) tracking and allocation, performance appraisal, training management etc

- project based Six Sigma approach for defect reduction and cycle time reduction.

Other initiatives include People CMM.

\subsubsection{Issues in Achieving High Maturity}

Identifying measurements for diverse business domains.

Application of control charts in small projects

Automation for metrics collection

Convincing customer about the need to improve process maturity to higher levels. 


\section{Preliminary Results of the 1999 High Maturity Survey}

The preliminary results of a survey of high maturity practices were presented to the workshop. The final results of the survey have been published as an SEI special report [Paulk 00] and represent inputs from 37 Level 4 or 5 organizations. The preliminary results were based on responses from 32 high maturity organizations from the 40 Level 4 and 21 Level 5 organizations known to have been assessed as of November 1999. This includes 26 non-US high maturity organizations: 24 organizations in India, with 14 at Level 4 and 10 at Level 5; one Level 4 organization in Australia, and one Level 4 organization in Israel.

Of the 26 high maturity organizations that participated in the workshop, 12 were from India, suggesting that the participation was reasonably representative of the worldwide high maturity community.

For the survey results, see <URL: http://www.sei.cmu.edu/cmm/cmm.articles.html\#hmp99>. 


\section{Working Group Reports}

Working groups were identified in eight areas:

- $\quad$ statistics

- assessments

- CMM integration

- measurement

- technology transition

- human issues

- reorganizations

- $\quad$ software quality assurance

There was sufficient interest in the working groups on statistics and measurement to split them into two different sessions; each is independently reported on in this section. No one signed up for the working group on reorganizations, so this working group was cancelled.

\subsection{Working Group 1: Statistics (Session A)}

Participants: Mark Amaya, Colin Benton, Bill Curtis (presenter), Rick Hefner, Pankaj Jalote, Keith Joyce, Barbara Kolkhorst, Jane Moon, Andre Heijstek, Steve Janiszewski, Mark Paulk (facilitator), Neil Potter, Leitha Purcell, Phil Sperling, Ramesh Venkatraman, Ramaswami K. Viswanathan (scribe), Don White (timekeeper), and Gary Wigle.

At the beginning of the working group discussion, a number of books on statistical process control (SPC) were recommended by Mark Paulk:

- Measuring The Software Process by WilliamA. Florac and Anita D. Carleton, Addison Wesley

- Building Continual Improvement: A Guide for Business by Donald J. Wheeler and Sheila R. Poling, SPC Press

- Understanding Statistical Process Control by Donald J. Wheeler and David S. Chambers, SPC Press

- Understanding Variation: The Key to Managing Chaos by Donald J. Wheeler, SPC Press

- Advanced Topics in Statistical Process Control: The Power of Shewhart's Charts by Donald J. Wheeler, SPC Press

- Short Run SPC by Donald J Wheeler, SPC Press 
A handout was also provided to expand on an earlier discussion on SPC terminology in the plenary session. In a column entitled "A Modest Proposal," Don Wheeler has recommended some changes in the traditional SPC terminology that may help address some of the misunderstandings of SPC, which is summarized in Table 1.

\section{Table 1: $\quad$ Wheeler's Proposed New SPC Terminology}

\begin{tabular}{|l|l|}
\hline Traditional SPC Term & Wheeler's Preferred New Term \\
\hline Statistical Process Control & Continual Improvement \\
\hline Control Charts & Process Behavior Charts \\
\hline In-Control Process & Predictable Process \\
\hline Out-of-Control Process & Unpredictable Process \\
\hline Out-of-Control Point & Point Outside the Limits \\
\hline In-Control Point & Point Inside the Limits \\
\hline Control Limits for Individual Values & Natural Process Limits \\
\hline Control Limits for Averages & Limits for Averages \\
\hline Control Limits for Ranges & Limits for Ranges \\
\hline
\end{tabular}

Paulk proposed a number of hypotheses regarding quantitative management as a starting point for the working group to discuss, which led to observations and recommendations. Five topics were voted of most interest to the participants. They proposed that a true maturity Level 4 organization can and will

1. show significant improvement trends in business results relative to process improvement

2. demonstrate capable processes at Level 4

3. control processes at the activity / step level of granularity on a day-to-day basis

4. demonstrate the application of quantitative management using "rigorous" techniques to control the design (architectural and detailed), coding, and testing processes (and probably requirements analysis)

5. identify causes of stratification in process data

\subsubsection{Observations}

The working group members were surprised that there are so many different opinions about what constitutes SPC. It was clear that there is little common understanding in the SEI and software process improvement (SPI) communities of what SPC and Quantitative Process Management (QPM) are or imply. SPC is new to the software community; it is easy to misapply, reach wrong conclusions, and make poor decisions.

One example of this is the use of sample standard deviation as an estimator for sigma when setting control limits. Any introductory statistics course teaches that the standard deviation of 
the sample approximates the value of sigma for the population. Since spreadsheet programs usually include a "stdev" function, it is easy to calculate 3-sigma control limits using "stdev." Unfortunately, there are several ways to estimate sigma, and the sample standard deviation happens to be a bad one for control charts because it combines common causes of variation (desirable) with assignable causes of variation (undesirable). This inflates the control limits - sometimes by factors as great as 3-5 times larger than they would be using the correct formulas (Don Wheeler, "Charts Done Right," Quality Progress, June 1994; Thomas Pyzdek, "How Do I Compute $\sigma$ ? Let Me Count the Ways," Quality Digest, May 1998).

Similarly, many of the problems with large variation in the software process may result from aggregating multiple processes, with a resultingly large set of control limits. One example reported at the workshop was for a control chart in which the 3 -sigma limits were considered too wide. A ruler was moved down the chart until, at about 1.5 sigma, "signals" were detected in the data based on a judgment that the testing error rates had been problematic. In this case, the main modules used to control the program had been considered simple, and an "abbreviated" process was used to build the main control modules. In testing, however, these simple modules turned out not to have been that easy to program. It was pointed out that this is actually an example of stratification - combining data from separate processes - in this case, the normal software process and an abbreviated process. There may, or may not, have been signals in the data for each of these processes, but it seemed clear that the abbreviated process was not capable of providing the quality needed for the main control modules.

The issue of large amounts of variation in the software process remains a significant one regardless of disaggregation techniques, such as identifying stratification. Individual differences are massive in intellectual activities such as software engineering. While teamwork, disciplined processes, and disaggregation minimize this intrinsic variation, no consensus was reached on whether organizations should expect to be able to apply control charts to the software process in all circumstances, although many examples of their application were mentioned.

The working group members observed that it is hard to establish the relationship between SPC and business objectives at the executive level. Quantification of benefits is not a common practice in most organizations regardless of maturity, but it was also observed that a true Level 4 organization can identify the business objectives it wants to control through quantitative management practices. It is easier to identify the relationships to intermediate business objectives, such as decreased cycle time and defect densities, than to executive-level business objectives such as increased market share and stock price. Many executive-level business objectives may be viewed as having only a tenuous connection to process improvement or quality.

The working group members observed that they only heard people applying quantitative management to a few processes, such as inspections and earned value analysis. There was a discussion on whether controlling the inspection of the design, for example, should be con- 
sidered as controlling the design process as well as the inspection process, since causal analysis may lead to problems in the design process as well as the inspection process. There was general agreement within the working group that few examples of control charts in the early phases of the life cycle, especially requirements analysis, were available. It was also noted that the high maturity practices survey indicates that control chart usage in the requirements phase is comparable to that in later life cycle phases.

\subsubsection{Recommendations for High Maturity Organizations}

The working group identified a number of recommendations for high maturity organizations to consider.

First, Level 4 organizations should provide the project teams with sufficient training, tools, and mentoring in statistical and/or modeling methods to apply appropriate quantitative management techniques effectively.

Second, data collection should be frequent enough to provide real-time control of the process. Whether this control should be on a daily or weekly basis was discussed, but no consensus was reached since circumstances may vary.

Third, understanding variation is required at Level 4, but not the use of control charts. A high maturity organization should choose the appropriate statistical or modeling technique to answer the specific questions that it has. Control charts are a powerful statistical tool, but many other rigorous techniques are possible, such as analysis of variance and regression analysis. One example of a non-SPC quantitative management technique that was mentioned is the weighted lateness technique developed by Telcordia Technologies.

Fourth, a Level 4 organization is not required to have capable processes, but it must understand the capability of its processes. Process capability implies a statistical understanding of the expected performance of a process in terms of expect mean and variation. Process capability indices are frequently used to compare expected performance based on 3-sigma limits versus the requirements (specification limits) for the process. A capable process is one that can satisfy its requirements in its normal operation, i.e., its 3 -sigma limits are within the specification limits. Even in a Level 4 or 5 organization, the requirements set for a process by the customer, whether internal or external, may not be achievable within current process capability.

There was an extended discussion about what a Level 4 or 5 organization can and will do about this. There are no guarantees of success, even in high maturity organizations, of adopting new processes that will be capable. In Level 4 organizations, disparities in process capability and requirements will be recognized, and the project may take corrective actionincluding changing the requirements - to address the problem. In Level 5 organizations, there is an ongoing systematic effort to improve process capability across projects. These organizational efforts may help projects address process capability problems, but high 
izational efforts may help projects address process capability problems, but high maturity promises an understanding of the problem rather than a successful resolution.

Fifth, continue disaggregating process control data until the chart is usable. Then people can take action on the data and be held accountable. Aggregated data is too variable by definition.

Sixth, the use of SPC in earlier phases of the life cycle, such as requirements analysis, should be institutionalized.

\subsubsection{Recommendations for the SEI}

The working group identified a number of recommendations for the SEI to consider.

First, the SEI should clarify to the SPI community whether the current operating model is

- Software CMM Version 1.1 as written

- Version 1.1 as reinterpreted, clarified, and elaborated in Software CMM Version 2 Draft C

- what we wish we had said when we wrote Version 1.1, which is not exactly what we said

The working group recommended the first option, Version 1.1 as written, at least until a replacement model, presumably based on the ongoing CMM Integration work, is provided. Although the SEI and the SPI community have learned much about quantitative management and SPC since Version 1.1 was released, for reliability and consistency, the operating model must be Version 1.1. There are concerns about inconsistency of interpretations, primarily at Level 4, and these need to be addressed, but it should be in the context of Version 1.1 as written.

Second, the SEI should clarify confusing high maturity issues in CMMI model for Level 4 at the goal and practice level. It was noted that the review period for CMMI v0.2, currently under review, ends November 30,1999, and the workshop attendees were encouraged to participate in the review, particularly from a high maturity perspective.

Third, the SEI should maintain flexibility in the range of quantitative methods that are legitimate (or required) at Level 4. Many different quantitative methods can be used to support quantitative management.

Fourth, the SEI should get input from more organizations in building consensus on high maturity practices, and disseminate this information for review and guidance to organizations that need its guidance.

Fifth, the SEI should publish a compendium of quantitative management practices (including examples other than SPC) currently in use and their benefits. 
Sixth, the SEI should request Lead Assessors to supply case studies on Level 4 and 5 organizations.

Seventh, the SEI should create guidelines for applying quantitative management techniques based on industry lessons learned.

Eighth, the SEI should not, however, be the final authority on statistics. This last point was inspired by a discussion of 2-sigma versus 3 -sigma control limits. Some high maturity organizations are using 2-sigma limits to trigger action, and it was observed that several SEI statistics experts have commented that these are not valid control limits. Paulk stated that, in his judgment, "action limits" based on 2-sigma were legitimately based on an understanding of variation and thus could be considered a valid quantitative management technique at Level 4. Some statisticians consider these to be valid control limits; other statisticians note that this is an explicit violation of Shewhart's rationale for choosing 3-sigma limits and state that 2sigma limits are incorrect. Given the rift in the statistical community on this issue, anyone using 2-sigma limits should be educated that this is not generally accepted practice, and the use of the term "2-sigma control limits," unless made in ignorance, is likely to be considered as taking a position in a heated debate that makes the proponent fair game. It is fair to say that most SEI staff knowledgeable in SPC are aligned with Don Wheeler's philosophies, so characterizing 2-sigma limits as control limits is likely to lead to a correction in terminology.

\subsection{Working Group 1: Statistics (Session B)}

Participants: Bijay Kumar Jyotishi, Anand Kumar, Walt Lipke, Andy Meadow, Mary Lynn Penn, Joseph Seppy, Rakesh Soni, Subramanyam V., and Charlie Weber.

\subsubsection{What is Level 4 Really Trying to Accomplish?}

Level 4 is an evolving interpretation using data, leading to statistical process control. The group discussed at length whether Level 4 is limited to ensuring the stability of the software process, or it also requires process improvement. Consensus on this issue proved elusive, although the vast majority of the members of the group believe that Level 4 is limited to stability of the software process.

One opinion raised during the discussion was that Level 4 is actually a transient level, between Levels 3 and 5. Organizations cannot really sustain Level 4, without moving towards Level 5. If they choose not to, they will probably slide back to Level 3. Obviously, this issue could not be discussed threadbare due to constraints of time.

The group agreed on the fact that Level 4 has a product/process/project orientation for process improvement, whereas Level 5 implies organization-oriented improvement. At Level 4, you need to reconcile the project's process capability with performance goals/commitments. In order to achieve this, the process must be planned and defined, along with attainable qual- 
ity goals that are consistent with one another. A related view expressed by some members of the group was that the planned processes must be based on past process performance, plus defined strategies, to address the estimated gap between past performance and the quality goals of the project. However, there was no consensus on this last point.

\subsubsection{How Can You Better Prepare for Level 4?}

In order to be geared for Level 4, organizations need to look ahead when implementing lower levels of the CMM. For example, the automation of data collection should be in place before getting to Level 4, so that the quantitative focus of Level 4 does not add overheads to the implementation of the software process. This look-ahead requires that members of the organization, who are charged with leading the software process improvement program at Levels 2 and 3, are trained on the higher level KPAs as well. For example, they should be able to understand that run charts could lead to control charts. The group felt that the M\&A KPA at Level 2 of the CMMI could facilitate this transition.

\subsubsection{Statistical Techniques}

What do we mean by statistical methods?

What new statistical techniques can we use when moving from Level 4 to 5 ?

Is there some way of classifying these techniques?

Do we have examples of where statistics have / have not worked?

After intense discussions, the group was able to reach consensus on the following classification of statistical techniques:

- "Startup" Techniques

- Computation of mean / mode / median

- Run charts

- "Startup / Intermediate" Techniques

- Histograms

- Pareto charts

- "Intermediate" Techniques

- Control charts

- Correlation charts

- Regression analysis

- Fishbone diagrams

- Rayleigh curves

- Orthogonal defect classification

- “Advanced" Techniques

- Process models / simulation 
- Analysis of variance / mean

- "Not Sure / Advanced" Techniques

- Multivariate analysis

- Design of experiments

- Prediction intervals

Members of the group were able to recount some of their experiences on statistical techniques that did or did not work in their organizations.

The following techniques appear to have worked:

- run charts for productivity, rework, and program measures

- control charts for program measures and quality (most organizations seem to use XmR for this)

- Rayleigh curves for defect prevention

- orthogonal defect classification for defect prevention, causal analysis, process change management, and technology change management

- correlation charts / scatter diagrams for the relationship between requirements volatility and product quality, and for predicting size against effort and defects

- regression analysis to estimate effort and schedule from size

- histogram for effort and schedule overrun

The following techniques appear to have not worked:

- run charts used on test defect data

- combining data from various domains and constructing histograms

- $\mathrm{u}$ charts for data that has large intra-sample differences

- usage of control charts in areas other than defects and program measures (members of the group did not have any examples on this)

- $\quad$ selecting measurements that are relevant to control charts, and that when plotted yield meaningful results

\subsection{Working Group 2: Assessments}

Participants: Al Aldrich, Mark Amaya, Julie Barnard, Colin Benton, Harry Carl, Donna Dunaway, Judah Mogilensky, Jane Moon, Joe Puffer, V. Subramanyam, Carolyn Swanson, Don White, and Gary Wigle.

Jane Moon (Raytheon) facilitated the brainstorming of the Assessment Working Group in order to collect issues that the group felt were the most important:

- consistency of assessment results 
- requirements for assessments

- training for the team $(\# 3)$

- assessment team members (\#3)

- lead assessors (\#3)

- organizational level 4 understanding of quantitative management (Curtis question 8) (\#1)

- Is SPC necessary?

- difference between quantitative techniques, statistical control, and SPC?

- number of subprocesses that need to be controlled

- training for level 4-5 (\#3)

- Institutionalization? length of time

- Do processes (under SPC) have to be capable?

- For TCM, what constitutes "new technology?"

- Is piloting required?

- Must use QPM/SQM for PCM/TCM? (And if not, what's the difference between $\mathrm{PCM} / \mathrm{TCM}$ and OPF/OPD at Level 3?)

- Does SPC require use of control charts?

- What project characteristics are required to institutionalize Level 4 ?

- Do we require a clear link from business goals to measurements (selected processes)?

- What constitutes "analyzed" below Level 4?

- How many types of measurements are required for Measurement and Analysis common feature (at any level)?

- What is a "measurement"?

- What are "minimum criteria" for Level 4?

- What are quality criteria under SQM?

- What defined process is required for PCM and TCM?

- What vehicles exist for disseminating CMM interpretations/guidance?

At the conclusion of the brainstorming, the group considered the question of what they wanted to accomplish. Did they want to focus on infrastructure or focus on making group interpretations? The goals of this session were determined to be

- developing guidelines on Level 4-5 interpretation. (All group members wanted to do this)

- creating mechanism for establishing and disseminating guidelines (all but three)

- to Lead Assessors

- to organizations working on Level 4-5

- establishing training and qualification of Level 4-5 Lead Assessors and teams (all but two) 
The group agreed to begin discussions on the second bullet "mechanism for establishing and disseminating guidelines." The discussion points included

- Re-establish CMM Advisory Board.

- mechanism for community ownership of model

- Establish accreditation criteria for

- Lead Assessors

- appraised organization

- Document this group's interpretation and send it out to everyone.

Copies of "SEI Strategy for Ensuring Valid Implementation and Appraisal of Level 4 and Level 5 Process Areas - October 28, 1999" were distributed. The document is attached in Appendix C. The group had a number of revisions that they wanted to recommend:

- Re-establish CMM Advisory Board. (Add to paragraph 1.)

- Establish mandatory supplemental training of any Lead Assessor (to lead Level 4-5 assessments). (Add to paragraph 1.)

- Gather data re/ "problem of inconsistent results at Level 4-5." (Add to paragraph 1.)

- $\quad$ Strengthen QA provisions for Lead Assessors. (Add to paragraph 1.)

- Periodically conduct High Maturity practices workshop. (Add to paragraph 5.)

- Elicit papers from the community at large. (Add to paragraph 6.)

- Identify criteria for qualified referees. (Add to paragraph 6.)

- Add Report of the Workshop Proceedings and mandate to grow further. (Add to paragraph 7.)

- Drop the word "informal" from title of paragraph 8. Re-title "Communications between the SEI and the CMM User Community."

After a short break, the group moved to training and qualifications of Lead Assessors and teams. Items discussed included

- One-day Level 4-5 training will be developed to supplement CMM model training (reflects CMM v1.1) (add to paragraph 3.c.)

- Courses to be offered by SEI need final peer review by qualified individuals in the community (e.g., by CMM Advisory Board or designees). (Add to paragraph 3.)

- "Continuing education" criteria and expectations will be established for Lead Assessors (for renewal of LA authorization). (Add to paragraph 4.)

- Require high maturity practices course (or defined equivalent) for Lead Assessors to lead L4-5. (Add to paragraph 4.)

- Require Lead Assessors for L4-5 assessments to have experience with assessments where L4-5 KPAs are in scope. (Add to paragraph 4.) 
- All requirements described for Lead Assessors apply to Lead Evaluators as well. (Add to paragraph 4.)

- Separate method training from model training. (Add to paragraph 4.)

The following recommendations were agreed upon:

- Make materials available through Transition Partners.

- Provide training in other geographic areas (e.g., Middle East, India, Australia, etc.).

The discussion moved to bullet one above: guidelines on Level 4-5 interpretation. Focus on SPC and "acceptable limits."

- SPC includes many techniques — and IS required for satisfying Level 4.

- statistical methods, including Pareto, ..., etc.

- control charts (or "process behavior" charts)

- limits established by "voice of the process" (stable) vs. "voice of the customer" (capable)

- other approaches: multi-variety analysis

- NOT arbitrarily set limits that are not process data driven

- based on a theoretical foundation

- finer granularity than Level 2

- Is there something I can change to get this process under control?

- Techniques applied to manufacturing do not necessarily apply directly to SW engineering.

- Does it meet the needs to the project?

- Is there a coherent rationale?

- QPM requires identification of critical subprocesses that are placed under statistical control.

- the understanding of the natural variation of the subprocesses ("voice of the process")

- Take action for "special causes of variation" (once you can recognize them).

- Limits are established by the "voice of the process" (stable).

- aware of process vs. voice of the customer

- NOT arbitrarily set limits that are not derived from the natural variation of the process (i.e., based on the natural performance of the process)

- SPC includes many techniques, and it is expected that

- Techniques applied to manufacturing do not necessarily apply directly to software engineering.

- Control charts, or "process behavior" charts are expected at a minimum.

- Statistical methods, including Pareto charts, histograms, etc., are included

- Other approaches may be used: multivariate analysis. 
- Quantitative management methods are in place to address issues of instability (that is, managers use the data to make decisions).

Next topic: Require a link between the business goals and the measurements

- related to the selected subprocesses

- Processes help achieve identified business goals.

Next topic: Number of subprocesses to be controlled

- critical subprocess, as applicable to your issues/goals

- Use (sensitivity) analysis to establish criteria for selecting "critical subprocesses."

- Not all processes/subprocesses need to be under quantitative control.

Next topic: PCM and TCM-Is piloting required?

- limited in scope

- applied when/where appropriate

- Some examples of piloting are observed (in assessment).

- Expect to see piloting (or prior use) before major changes.

- Organization has defined criteria for piloting.

\subsection{Working Group 3: CMM Integration}

Participants: Dottie Acton, Julie Barnard, Rick Biehl, Mary Lynn Penn, Neil Potter, Warren Schwomeyer, and Ramesh Venkatraman.

A collaboration of government, industry and the Software Engineering Institute is integrating the Capability Maturity Models (CMM) with an objective of making the CMMI models an international standard.

Participants in the High Maturity Practices Workshop of November 1999 discussed various issues pertaining to CMM Integration. Mary Beth Chrissis, SEI, facilitated the discussion, and the participants were from matured organizations that are all following the CMMI practices. Refer to the annexure for participating organizations' names.

The participants listed out the points for discussion and all the stated points were voted for priority. Based on the voting, the following items were prioritized and the report is summarized.

- CMM Global Issues 
- impact of the CMMI

- continuous v/s staged

- $\quad$ statistical $\mathrm{v} / \mathrm{s}$ quantitative

- things to worry about

- normative $\mathrm{v} / \mathrm{s}$ Informative

The participants also presented the gist of the discussions during the workshop, and this report is the collective work of the working group submitted to the SEI. This report expresses the concerns and the suggestions for improvement with respect to CMM Integration, with an intention of what shall be done further by the SEI on CMM Integration for the benefit of practicing organizations.

\subsubsection{Impact of CMMI}

The Integrated Capability Maturity Model (CMMI) is an excellent representation of both Software and Systems Engineering practices. Industry, as it has matured in one area, has consistently defined weaknesses in associated areas. The partnership of the two disciplines is both necessary and welcome.

Industry, however, has adopted other models to guide improvement in associated areas. These areas include Human Resources/Training (People CMM), Subcontract Selection and Management (Software Acquisition CMM), and the increased need to adopt IPPD. In order to assure industry that the CMMI is indeed "THE" model, a plan should be made public with details of further model integration.

Particular impacts to industry were also enumerated; some of these are discussed in more detail in other sections:

1. Peer Review Key Process Area (KPA): In the past versions of the SW CMM, Peer Review was called out as a stand-alone KPA. It was this KPA which gave much of the foundation as maturity progressed. Forcing the introduction of a formal peer review at Level 2 assisted organizations in establishing quality goals, associated metrics and prevention activities. The incorporation of peer reviews into generic review processes will diminish the importance of the practice itself.

2. Measurement and Analysis Process Area (M\&A PA): In the past versions of the models, measurements had been a Key practice associated with every process area. The focus of measurement and analysis as a separate Process Area gives importance and concentration to the activity and lays a stronger foundation for improvement and quantitative management.

3. Risk Management PA: The addition of this process area was a strong indication of the added importance of quantitatively managing the process. Although the PA is very complete in discussing the relevance and mitigation of risk, it is noticeably silent on the managing opportunities. 
4. Quantitative Process Management: The new model clearly articulates the meaning of quantitatively managing as it relates to quantitative control.

5. CMMI introduction: There is the obvious tendencies in the beginning sections to "defend" versus introduce the model. There is an overload (63 pages) of "apple pie"; for the novice user this would not solicit the adoption of the model.

6. Continuous versus Staged: Although this will be discussed in later sections, the general opinion was that educating the user in the CMMI Process Areas and the need to establish good practices is a significant challenge. Educating the user in the benefits of continuous versus staged is overwhelming. One representation needs to be adopted.

7. General Format: The CMMI program needs to make industry aware that the "packaging" was dictated by the desire to adopt the CMMI as an international industry standard.

8. Normative versus Informative Model: This topic also is discussed in later sections. The normative model is an excellent representation from the assessor's point of view. The number of work aids included in the model caused confusion and was over burdening. Separating the normative and informative emphasized the difference.

It is important for industry to understand that there are issues and differences. Encouragement to embrace the model will come with evidence of its usefulness and ease of adoption.

\subsubsection{Things to Worry about for Level 4 and 5 Organizations Adopting the CMMI}

This worry list stems from a) scope changes found in CMMI, and b) the interpretation problems likely to arise for an assessor.

\section{Level 2: Data Management}

Data management could be interpreted by an assessor as the management of program and project data under Configuration Management. In this case, there is no worry. It could also be interpreted as the management of data that you have never managed before. That could cause a surprise in an assessment.

\section{Level 2: Supplier Agreement Management}

This Process Area now includes all significant products and services acquired to make your projects successful. There is much room for interpretation (and therefore room to be assessed Level 1!). Read the CMMI carefully, and check the following with your assessor:

- Does the assessor interpret "Supplier" to mean only those products you purchase that are delivered to your customer? Or is "Supplier" interpreted to mean all products and services purchased for your project, regardless of whether or not they are delivered to your customer? In the Intro to CMMI-0.2 class, the SEI instructors did not agree on this issue.

- How does your assessor define "service"? Assessors might differ greatly in their interpretations of what a service is, and which ones come under Supplier Agreement Man- 
agement. I have not found a good definition of "service" in the CMMI yet. The SEI gives examples of product help-desk support, post-delivery product consulting, and customer training.

\section{Level 2: Project Planning and Control Process Areas}

The process areas state that products and services need to be planned and tracked. "Services" might include product help-desk support, post-delivery product consulting, and customer training. If an assessor has this interpretation, these business functions will be assessed. Are yours Level 2/3/4/5?

\section{Level 3: Decision Analysis and Resolution}

This process area requires the need for a generic decision analysis process for making important decisions. If you do not formally have one of these, you would be assessed at Level 2.

\section{Assessing Combined Systems Engineering and Software Engineering Groups}

Some assessors might insist that both systems and software engineering groups be assessed in one assessment, since the CMMI naturally covers both disciplines. However, the systems group might be at Level 2, and the software group at Level 4. A combined assessment might lead to difficulty in determining prevalent strengths and weaknesses.

Make sure your assessor understands the correct assessment scoping rules currently present in the CBA-IPI method, (and whatever is in the upcoming SCAMPI method). CBA-IPIs can scope the assessment in many ways, as long as this scope is clear in the findings.

\section{Continuous View}

Level 5 in the staged view is not the same as Level 5 in the continuous view. Level 4/5 in the continuous view requires that the measurements of all the process areas be under statistical control. This can be meaningless for some process areas, such as CM and Risk Management.

\subsubsection{CMMI - Normative versus Informational Models}

Each representation of the CMMI (continuous and staged) has two models: the Normative and the Informational. The discussion centered on understanding the differences between the models and identifying some of the concerns associated with one or the other of the models or with having two models.

There was a general concern expressed regarding the sheer volume of material associated with the CMMI. Obviously one contributing factor is the presence of both a Normative and Informational Model for each representation of the CMMI. The inclusion of the Normative Model within the Informational Model also adds to the total volume of material. In contrast 
to the recommendation to have only one CMMI representation, the group did not reach consensus on the desirability of having only one CMMI model.

The SEI provided insight into the origin of the Normative Model. The packaging of this model is influenced by the need to support making the CMMI an international standard. As evidenced by EIA/IS 731, an international standard contains considerably less detail than the Informational Model. To satisfy this need, a recommendation was made to the SEI to reduce the size of the Normative Model even more (to 20 pages), call it a Standard and provide reference to the Informational Model for all of the descriptive material associated with understanding and interpreting the standard.

The higher level of abstraction provided by the Normative Model was viewed to have both benefits and drawbacks for low maturity organizations. On the one hand, it was felt this abstraction would help prevent low maturity organizations from 'nit picking' the model and getting bogged down in minutia in one Process Area, or at one level, while ignoring other practices which would have a more beneficial effect on their operations. At the same time, it was felt that a low maturity organization could miss the beneficial points of a Process Area described in the Informational Model or use this abstraction to intentionally get away with less rigor through "interpretation" of the Normative Model.

This perspective that the Normative Model is "watered down" and "more abstract" when compared with the Informational Model raised questions as to whether one might be too little and the other too much. A contributor to this perspective may be related to the use of bold type to indicate the required portions of the model. The textual wording of the practices is bold type in the Informational Model and regular type in the Normative Model indicating a difference in the requirements. This leads to the conclusion that the practices in the Normative Model are at a higher level than in the Informational Model. If there is to be one operative model, it must be more clearly communicated how compliance to either of the two documents should result in similar and equally mature processes.

Related to the concern of implementing a more or less abstract model is the concern of being assessed to a more or less abstract model. Questions raised included

- Will assessment to the Normative Model be more subjective with respect to assessing to differing interpretations of the goals and practices?

- Will assessment to the Informational Model be "nit picking"' down to the information in the sub and sub-sub-practices?

- Will assessors be given enough training and guidance to perform consistent assessments irrespective of the model used?

Consistency of assessment results is critical to the effective use of the CMMI (as with any maturity model). It was indicated that it is necessary for organizations to provide feedback to the SEI about their assessments and assessors in order to help ensure consistent assessments. 
The SEI indicated to the group that there are currently inconsistencies in the level of detail in defining some of the practices in the Informational Model due to adhering to schedule constraints in releasing the CMMI. The next release of the model is expected to correct these inconsistencies.

\subsubsection{Continuous versus Staged}

This topic addressed the relative advantages and disadvantages of the two different model implementations, concerns with the differences between the models, and recommended that the SEI adopt one or the other, but not both.

\section{Advantages and Disadvantages}

One advantage of the staged model is that it is easy to get started with, because people can box themselves at a level and work toward one level at a time. Of course, this has a corresponding disadvantage that people will look only at the current level rather than trying to gain an up-front understanding of the entire model. This up-front understanding would influence their implementations at lower levels in order to make the higher levels more easily achievable.

The corresponding advantage of the continuous model is that it encourages looking across the entire model initially, which facilitates the creation of a firmer foundation at lower levels. It also encourages an organization to think about what its issues are and pick those areas that are most relevant to its organizational issues and concerns. A mapping is available that shows which areas to pick in order to parallel the staged model, but there is no requirement to pick that set, or to implement all practices in a category at one time. This allows a more natural progression of maturity across each process area based on business needs.

\section{Concerns}

The most obvious problem of the continuous model is that it breaks down at Levels 4 and 5 because of the application of Level 4 and 5 generic practices to each process area. With the continuous model, in order to achieve a Level 5 rating in each process area, the processes for each area must be quantitatively managed, have quantitative improvement objectives and be measurably improved. Contrast this with the staged model, where the emphasis is on selecting the processes that can benefit most from quantitative management and improvement.

An examination of the current Level 5 organizations might make this concern clearer. How many of the current Level 5 organizations have some or all of their SQA, SCM, SSM, OPF and OPD processes under quantitative management? This would be required for a Level 4 rating against the continuous model, whereas with the staged model, most Level 5 organizations have selected to quantitatively manage and improve only some processes (inspection, testing, requirements management, etc), not processes from every process area. 
Another area of concern, other than the assessment issues, is that the two models do not appear to be equivalent. There are more practices in the continuous model since the level 1 practices and higher level practices do not show up in the staged model. For example, in the Customer and Product Requirements process area, there are 10 activities in the staged model, and 12 specific practices in the continuous model. The first difference is that the staged model has a Level 1 specific practice, Collect Stakeholder Needs, which is not in the staged model. However, the Elicit Needs practice and other related practices are in both models, so this is not too troublesome. The second difference, however, is more significant. The continuous model has a Level 4 practice, Perform Quantitative Validation of Customer Requirements, which is not in the staged model. This is particularly troublesome, because it is yet another way in which a Level 4 rating against the continuous model is more stringent than a Level 4 rating against the staged model.

\section{Summary and Recommendation}

By a 9 to 1 vote, the group preferred the continuous model. However, the caveat associated with this is that the requirements for assessment at the higher levels must be clarified, or it must be made explicit that the bar is being raised as to what it means to be a Level 4 or 5 organization when using the continuous model.

By a unanimous vote, the group preferred their second choice of model to having two models. It was felt that the complexity and confusion introduced by having to choose between models and to reconcile ratings against two models was not balanced by the advantages of either model.

\subsubsection{Statistical versus Quantitative}

The working group discussed a distinction that they felt was often being missed when discussing higher levels of process maturity; namely, the distinction to be drawn between quantitative techniques generally and statistical techniques specifically. The working group agreed that the latter group represents a subset of the former, but agreed that virtually any discussion of data at higher maturity levels seems to concentrate only on the narrower statistical category.

While a more detail discussion of the various techniques was presumed to be going on in the various measurement working groups, this working group chose to concentrate on the requirements for using this distinction, and how such requirements are, or should be, reflected in the CMMI.

Relevant requirements that were elicited during the discussion concentrated on the purposes to which data was being put in the process improvement arena, allowing such purposes to drive the choice from among the various quantitative techniques. 
While the majority of participants in the group were using SPC in their organizations, all agreed that an organization should be concentrating on statistical control only when rigor is required beyond that which can be achieved through less formal quantitative techniques. Specifically, more rigor is required when emphasizing long-term systemic change, or when the emphasis is on reducing variance rather than shifting the mean, and when situations arise where change agents strongly feel that outliers are heavily influencing analysis.

All agreed on the importance of measurement and analysis rigor, and all agreed that statistics generally, and SPC specifically, can and should be used to drive such rigor. But the group also acknowledged that many lower level maturity organizations view statistics as a "wall" that needs to be scaled in order to improve maturity. The shift to statistics is not viewed as smooth, and can be an inhibitor to organizations choosing to progress toward higher maturity levels. There is also considerable concern over the criteria assessors should use when evaluating an organization's use of these techniques.

The group observed that the CMMI tends to describe quantitative requirements that are almost universally interpreted by readers as statistical requirements. The distinction should be better drawn in future versions of the model. Normative descriptions should emphasize requirements for quantitative analysis, while informative descriptions might cite more and deeper statistical examples and applications.

Higher maturity organizations typically have had success with statistical techniques. Understandably, they want to encourage lower maturity organizations to adopt these techniques as part of their process improvement activities. However, such enthusiasm must be tempered with the realities and how such movement is perceived by lower maturity level organizations. Applied too soon, to unreliable low maturity data, statistics can be time-consuming and counterproductive. The CMMI, with its emphasis on applications of all process areas across the maturity spectrum, must recognize and support this distinction.

\subsubsection{Theory versus. Practice}

The working group observed that the CMMI represents a vast expansive model when compared to the previous software CMM. This expansion discussed is qualitatively different than the simple expansion of scope brought about with the integration of software and system engineering models. The distinction discussed is inherent in any shift from staged to continuous, as discussed previously.

By shifting to a continuous model, the user of the CMMI is theoretically responsible to apply all general practices to all process areas. In practice, this will not be possible for all users, particularly lower maturity organizations. Higher maturity users of the SW-CMM have little difficulty acknowledging and describing how, in theory, the staged model can be interpreted as continuous. Every KPA, regardless of the maturity level to which it has been defined, can be applied at every maturity level. In practice however, presenting the SW-CMM as a staged 
model made such interpretation unnecessary for lower maturity organizations unable to see such distinctions for themselves.

The group discussion resulted in a core theme; namely, does the continuous model actually work in theory, or might its application lead to unintended negative consequences in practice? An example discussed at length was the Quantitatively Manage Process Performance practice. Can (or should) this be done practically for every process area, or is it only theoretically possible? The group did not try to pursue the question to a complete answer, rather focusing on the role that the CMMI model can or should play in providing such an answer.

The issue carried weight among group members because of the assessment implication of the implied choices. Participants acknowledged that often such practice-level choices are made simply to remain competitive with other organizations that are perceived to be conducting certain practice in certain ways. This decision environment requires better informational support from the CMMI than was required under the old model.

The group recommends that the CMMI be developed to include more extensive work aids to provide meaningful paths through the model; aiding some of the theory-to-practice decisions that must be made. The group acknowledged that such information needs to arise from the community of users, and that the SEI is not in a position to make such in-practice decisions for the user community. However, the SEI can be a key facilitator in moderating such a flow, and assuring that the theory-practice decisions being made in the user community are synchronized with the expectations of the assessment process. Without such synchronization, poor decision making is likely to follow even in higher maturity organizations.

\subsection{Working Group 4: Measurement (Session A)}

This session included the following participants:

- Bhaskar Chavali, NIIT

- Ellen George, Allied Signal

- Kelly Gunning, Marconi Integrated Systems

- Rick Hefner, TRW

- Barbara Hirsh, Motorola

- Bijay Kumar Jyotishi, WIPRO Systems Ltd.

- Barbara Kolkhorst

- Andy Meadow, PRC

- Michael Scott, Raytheon

- Charlie Weber, SEI

A variety of measurement-related topics were identified, but two were selected as most important. Discussions follow. 


\subsubsection{Linking Business Goals to Project Goals and Measures}

One of the difficulties high maturity organizations face is the linkage between high level business goals and the project level goals and measures, and how software fits in to help achieve the goals. The difficulties begin with the definition of the business goals themselves, and how they are interpreted down through the organization to the projects and individuals.

Business goals are often defined or created by high level management and tend to be more of slogans rather than goals. They are very often not stated in a quantifiable way (e.g., "Improve Shareholder Value," "Increase Market Share," "Employee Satisfaction," "Customer Satisfaction"). Without quantifiable goals it is difficult to assess success against the goal. This can lead to different interpretations of the goal so that the resulting lower level goals become widely varied.

Another problem with some business goals is that they are not grounded by realism. Stretch goals are a good thing, but there must be some chance of success or there will be no buy-in in the organization. Goals that are obviously unachievable are identified easily by personnel in the organization and can actually result in not being able to achieve any of the goals due to credibility. Additionally, unrealistic goals at the organization level often result in unrealistic project goals. Business goals should be based on the capability of the organization. One of the practices that help achieve this is the Balanced IT Scorecard Method, available at <URL: http://www.esi.es/Publications/Reports/ME99TR014.html>, that brings all of the stakeholders into the goal setting process.

Project level goals must be mapped to the organizational goals and must be quantifiable, and achievable (even if organization members must stretch to achieve them). One of the difficulties projects have in establishing their goals is the short-term view of the project (e.g., get the product out in the given timeframe) versus the long-term organizational view (e.g., business growth). This tactical versus strategic conflict can sometimes result in conflicting goals that must be acknowledged and accounted for, if not eliminated. A practice that has been successful in establishing project goals is the Goal, Question, Metric (GQM) paradigm, available at <URL: http://www2.umassd.edu/SWPI/ESEG/localmat.html\#gqm>. In this method we establish a goal, question whether the goal is adequate, quantifiable, achievable, linked to higher level goals, and then establish a measure or metric to determine success against the goal.

The final issue that is related to this topic is the linkage of incentives (both positive and negative) to the goals at each level. Without incentives the question will always be "Why should I care about this goal? Incentives can take form at all levels (e.g., organizational, project, team, individual) and should be timely. One organization's practice is a formula for annual bonuses that are based on individual performance, team performance, organizational performance, and partnering with other organizations in the company. 
The establishment of meaningful goals at the project level for products, processes, or individuals starts with the definition of the higher level organization or business goals. These goals must be quantifiable and achievable, and must then flow through the organization. Links must be made between the business goals and the project goals and measures put in place to assess success. All of this requires an enlightened senior management structure that is willing to let the organization help in establishing the business goals. There are many best practices being used in high maturity organizations, but there is nothing standard across the industry.

\subsubsection{Similarities and Differences in People Issues between Lower and Higher Maturity Levels}

It was the consensus of the group, after discussion, that there are behavioral clues that are indicative of the maturity level of the organization. That is, organizations of different maturity levels behave differently. The following ideas were developed.

There are differences:

- Buy-in is a continuous process. But buying in to CMM SW Levels 2 and 3 does not automatically lead to buy-in for Levels 4 and 5. Re-contracting with the organization is needed each time to convince the members and managers of the value of the improved level. At higher levels, members of the organization can see the values of earlier practices, and buy-in deepens.

- At the early levels there is the introduction of discipline; at the higher levels the organization must add and refine the existing discipline.

- There is a shift in motivation at higher levels. The organization moves from escaping pain to seeking improvement opportunities.

- Process maturity does not always equal emotional maturity. There are defensiveness, posturing, and politics at all levels.

- Humans often choose the familiar and comfortable over the unknown.

- Understanding and commitment are deeper at the higher levels. Compliance and rote works at lower levels, but employees need internalization and understanding for higher levels.

There are similarities:

- There is no change in who must buy in. All types of people must buy-in at each level: the staff to report and analyze data and the managers to use the data properly.

- Development of and conformance to process is an evaluation factor for everyone in the organization. 


\subsection{Working Group 4: Measurement (Session B)}

Participants: Russ Campbell, Bill Curtis, Andre Heijstek, Pankaj Jalote, Keith Joyce, Walt Lipke, Ray Madachy, Leitha Purcell, John Smith, Rakesh Soni, Prathima Srinath, M.Thangarajan, and Dave Zubrow.

The following individuals assumed the following roles:

- Dave Zubrow, Morning Facilitator

- Russ Campbell, Afternoon Facilitator

- Leitha Purcell, Scribe

- M. Thangarajan (TH), Timekeeper

- Ray Madachy, Presenter

\subsubsection{Observations}

The group began by selecting a focus for its discussion. The initial discussion focused on identifying measurement issues associated with implementing measurement in higher maturity organizations. The intent was to identify what challenges were unique to measurement in ML4 and ML5 organizations. While some unique issues were identified, much of the list included challenges for measurement in any organization. One interesting observation is that these challenges that may be found in low maturity organizations may also be present in higher maturity organizations.

The group reached consensus on pursuing three topics in depth:

1. data quality and cost of data collection

2. capability baselines - creation and use

3. tying software quality to business objectives and identifying the relevant process measures

\subsubsection{Data Quality and Cost of Data Collection}

With respect to the first topic, it was noted that as the organization matures it requires data of increasing accuracy and granularity. This implies data should be recorded as close to realtime as is feasible. This may mean that effort data are recorded daily and other data are recorded as part of the event that generates them (e.g., a review, test or inspection). These requirements were viewed as driving up the costs of data collection. For instance, data may need to be collected more frequently and in more detail. A third component of data quality addressed the willingness of engineers to record defects. As targets are set for internal quality checkpoints, this may motivate some underreporting of defects. It was mentioned that it is important to continually communicate the use of the data being recorded. 
Finally, the group seemed to support the statement that the data collection done in support of achieving ML3 is of little value with respect to the use and needs of data at ML4. The exception to this that was noted was inspection data. However, one participant during review of the summary felt this statement was too strong. Rather, they believe that the data collected at ML3 may not be sufficient to support the needs of ML4, but that it sets the stage for accomplishing ML4. In particular, the collection of data around Software Product Engineering will help establish lifecycle data collection and analysis. Similarly the measurements around Integrated Software Management set the stage for continuous improvement at ML5.

\subsubsection{Capability Baselines - Creation and Use}

The second topic, capability baselines - creation and use, is one more uniquely associated with ML4 and ML5. Capability baselines are established as a result of analyzing performance information. For baselines to be useful, they need to be based on the experience of similar projects or process enactments. In many instances, some sort of subgrouping of the data might be desirable such as by business area or type of activity (e.g., maintenance vs. development). Additionally, as also discussed in the Statistics working group, the need to establish capability baselines based on nominal process executions was noted. Not allavailable data will be appropriate for such a use.

Of some concern to the participants was the seeming conflict between developing capability baselines and the expected culture of continual improvement at higher maturity levels. Participants wondered, if the process is continually changing, how is a meaningful capability baseline to be established? Indeed, measuring capability as distinct from measuring improvement was voiced as an area of confusion. During review of the draft report, it was noted that this distinction is important and the following explanation and example was offered. "This is a very important concept in understanding the difference between ML4 and ML3 and ML5. ML4 is not about process improvement; it is about process management. There is a close analogy here to the hardware world were calibration equipment is used to make sure the hardware is operating per design. Similarly in software, 'calibrated processes'

such as an inspection process, which is kept stable with a known capability, are used to make sure the other processes such as requirements, design, and integration are performing as designed."

Another issue, noted as somewhat vexing, was what the heuristics should be for selecting processes and process attributes for monitoring and control? One participant noted that their organization process capability baseline was composed of 20 or so attributes. While projects would only control 6 - 12 of those attributes, which ones would be controlled was not well defined. Guidance based on the nature of the project had yet to be defined. One example discussed was a process for aligning program goals and customer expectations with organizational goals. This provided insight as to which processes should be placed under quantitative control. 
Another issue involved making comparisons early during project. It was noted that due to the paucity of available data during the early days of a project, little insight was gained by comparing the data with a capability baseline.

\subsubsection{Tying Software Quality to Business Objectives and Identifying the Relevant Process Measures}

The final topic discussed involved tying software quality to business objectives and identifying the relevant process measures. The measures may address process efficiency, effectiveness, and compliance. It was generally agreed upon by the participants that measures need to be linked to business drivers and that the characteristics of the processes will constrain the possible set of measures and determine their operational definitions. A particular challenge to doing this effectively is the different perspectives, terminology, and motivations that need to be aligned. Making this linkage work requires vertically traversing many layers of processes and perspectives within the organization. And, as the organization increases in maturity, the scope of involvement within the organization will expand: more people will be involved in identifying and using software measures.

\subsubsection{Recommendations for High Maturity Organizations}

With respect to the first topic, data cost and quality, the following recommendations were expressed.

Do

Enforce the idea that staff who generate data should get to use it.

Model the behavior to have projects use data by having measurement group work with projects.

Keep the linkage to use and goals.

Keep clear whether measures are for the enterprise or for the process only.

Have statisticians and practitioners collaborate on defect and effort analysis.

Define analysis at same time as defining measures.

Have clear process definitions and define measures as part of defining processes.

Have management pull for need for data.

Have common measurement criteria.

Don't Fragment collection and use completely.

Enter the same data multiple times.

Bite off more than you can chew.

With respect to the second topic, capability baselines - creation and use

Do Explore data to understand points associated with special causes of variation.

Let downstream processes (e.g., testing) set specs for upstream processes (e.g., defect de-

tection activities like inspections). 
Also see the report on Statistics for related observations and recommendations.

With respect to the third topic, tying software quality to business objectives and identifying the relevant process measures

Do Define process requirements like you would a product requirement.

Look at processes that are involved and audience to identify measures.

Look at products that are result of process to identify entities to measure.

Identify critical dimension of requirement (cost, schedule, quality) as attributes for measurement.

\subsubsection{Recommendations for the SEI}

No specific recommendations were made for the SEI.

\subsection{Working Group 5: Technology Transition}

Participants: SuZ Garcia, Steve Janiszewski, L. Ravichandran, Prabhuu Sinha, and Eileen Forrester.

\subsubsection{Goals of the Working Group:}

The members of the technology working group framed the goals as a set of questions we would like to be able to answer:

- Are the issues of high maturity organizations common to our organizations?

- What actions can we recommend for common problems?

- What are the differences between our issues and others?

- How do we integrate technology deployment with process deployment?

- Why isn't technology deployment emphasized earlier in CMMs?

- What are the common barriers to technology deployment?

- Among high maturity organizations?

- Between high and low maturity organizations?

- When are different technologies optimally introduced?

Not all of these questions can be adequately addressed in a one day working group. However, they provided the framework and focus for the discussions that occurred throughout the day.

These goals translated into several themes, of which the first two were selected for particular focus: 
- processes for technology adoption

- cultural issues in facilitating technology adoption

- "systems view" of technology adoption

- tools to support technology adoption (i.e., knowledge management, technology adoption process support)

\subsubsection{Approach}

To address the goals of the working group, two approaches were agreed upon:

- Enlarge the small team (4) by adding a "virtual" team -- the 25 participants in the Summer 1999 Workshop on Managing Software Innovation and Technology Change, represented by Eileen Forrester of the SEI [Forrester 99].

- Use a couple of the models from the MSITC Workshop as a basis for framing issues and best practices.

The two models used from the workshop include the Strategic Planning model used by Litton/PRC and the INTRo (Introducing New Technology Rollout) model being worked on by the Accelerating SW Technology Adoption [Levine 99]. The Litton-PRC model provides a framework for understanding how explicit technology change management can provide a link between the goals of the business and the performance of the tasks of the business. The INTRo life cycle presents a set of phases and tasks that can be used to plan and manage the introduction of complex technologies into one or more organizational units.

Below is the Unifying Truism from the MSITC workshop:

People's ability to learn and absorb change is the new constraint on the speed of technology adoption.

This statement from the Summer 99 MSITC Workshop resonated strongly with the experiences of the technology working group members. It emphasizes the importance of the human issues over the technical issues related to technology adoption.

\subsubsection{INTRo as a Basis for Identifying Issues/Best Practices}

The major phases of the INTRo life cycle are diagrammed below. These phases were used to frame the answers to two questions that all members of the working group worked on answering for their own organizations' experiences:

1. What are the practices that most contributed to their success in performing technology management processes?

2. What are the issues that still provide challenges to their organizations, despite operating at high maturity levels? 
The tables following the diagram provide the critical success factors and the issues that were identified, as well as comment that arose in discussing these elements.

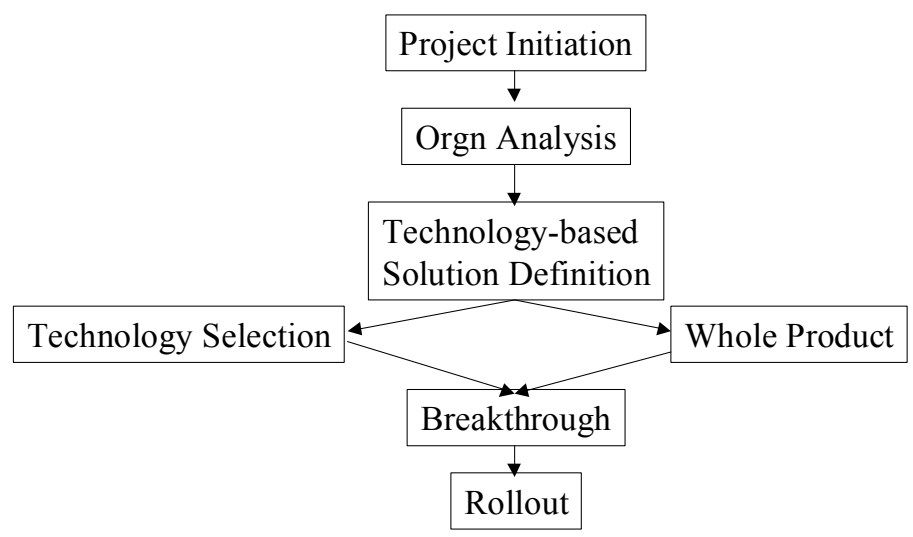

Figure 1: Major Phases of INTRo Life Cycle

Note that the columns in the tables below do not necessarily represent parallel issues.

\section{Table 2: $\quad$ Critical Success Factor and Issues for Project Initiation}

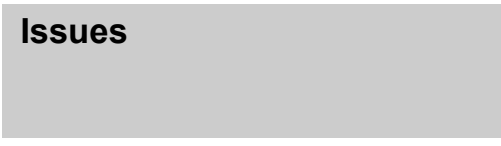

Solution is often pre-ordained.

Limited resources mean that establishing ownership for a proposed innovation is often an issue

Too busy_- "If it ain't broke don't fix it."

\section{Critical Success Factors}

Practices from strategic planning often mature ahead of or in parallel with TCM practices.

Benchmark against relevant companies to identify potential areas of investment.

Track emerging technologies with process group staff or other full time (non-project!) staff.

\section{Notes either on the Issue (I) or the Critical Success Factor (C)}

(I) Not that common unless related to strategic issue.

\section{Table 3: Organizational Analysis}

Issues
$\begin{aligned} & \text { Lack of shared process, model, } \\ & \text { etc for learning and communi- } \\ & \text { cating about cultural/social issues }\end{aligned}$
$\begin{aligned} & \text { Difficult to determine when the } \\ & \text { scope of impacts has been cov- } \\ & \text { ered }\end{aligned}$

\section{Critical Success Factors}

Include support functions and other relevant stakeholders early/at this stage.

Find ways to bring in "social science" experts to help.

\section{Notes either on the Issue (I) or the Critical Success Factor (F)}

(I) Less prevalent w/single-site or single-discipline organizations

(I) Not as prevalent with single site organizations

(F) Still many cultural barriers to social scientists participating with engineering organizations 
Table 4: Technology-Based Solution Definition

Issues

Difficult to dissociate the technical from the practical .

Market constraints that lead to internal technology development can lead to large long term costs.

\section{Critical Success Factors}

"Proposer" of technology adoption follows through with ownership on implementation.
Notes either on the Issue (I) or the Critical Success Factor (F)

(I) Solution definition vs. technology selection.

Also a practice to mitigate tendency toward lack of ownership in project initiation

Table 5: Technology Selection

\begin{tabular}{l|l|}
\hline Issues & Critical Success Factors \\
\hline $\begin{array}{l}\text { Generally not enough } \\
\text { time/resources to scan all relevant } \\
\text { alternatives. }\end{array}$ & $\begin{array}{l}\text { "Technology selection board" } \\
\text { including: } \\
\text {-techies } \\
\text {-business planners } \\
\text {-managers }\end{array}$ \\
\hline $\begin{array}{l}\text { "Fire Ready Aim" - not as } \\
\text { prevalent as we matured, but still } \\
\text { a "gotcha" sometimes. }\end{array}$ & $\begin{array}{l}\text { "Internal competency center" fo- } \\
\text { cusing on common needs for sup- } \\
\text { porting technology implementation }\end{array}$
\end{tabular}

\section{Notes either on the Issue (I) or the Critical Success Factor (F)}

\section{Table 6: $\quad$ Whole Product Definition/Development}

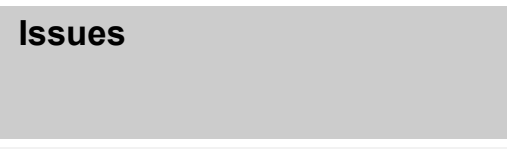

Whole product not perceived as the "real" technology.

Often difficult to "synchronize" involvement of the relevant stakeholders.

Whole product is often incomplete (it isn't just training!).

Feedback mechanisms for refining whole product often missing.

\section{Critical Success Factors}

Involve "pilot" groups in whole product definition/development to accelerate buy-in.

Train teams together - "boot camp" - plus support them with mentoring.

See the pilot teams as the "customers" for the whole product.

\section{Notes either on the Issue (I) or the Critical Success Factor (F)}


Table 7: Breakthrough

Issues

Getting the right staff at the right time.

Initial pilot works but rollout steps are not sufficiently worked out (especially in project-focused cultures).

Finding the time to train team in new technology prior to start of the pilot.

Difficult to find credible and relevant pilots.

\section{Critical Success Factors}

Add mentors/coaches from process group staffing/budget to add incentive to pilot teams to participate.

Interview pilot candidates to determine their suitability a la technology adoption curve.

Be sure to collect before/after data and info.
Notes either on the Issue (I) or the Critical Success Factor (F)

\section{Table 8: Rollout}

\section{Issues}

"Long" (e.g., 3 years) life cycle of projects dilutes ability to sue pilot results in rollout.

Multiple technology adoptions over a short period of time increases confusion/resistance.

How to move from successful pilots to widespread adoption with project-focused culture unclear.

\section{Critical Success Factors}

"Sell" the breakthrough and relate it to the organizational objectives.

Advertise the objective evidence.

Provide feedback to improve the whole products so organization rollout is more effective.

Plan for a range of technology adoption curve populations in the pilots/rollouts.
Notes either on the Issue (I) or the Critical Success Factor (F) 


\subsubsection{Strategic Planning Insights}

The diagram below is an adaptation of Litton-PRC's model of connecting technology management with strategic planning (the major adaptations were to orient the model toward a general business context rather than toward a contract business model). Below the diagram are the comments made by working group members. The main function of this model in the working group was to provide an organized framework for much of the experience that they had had.

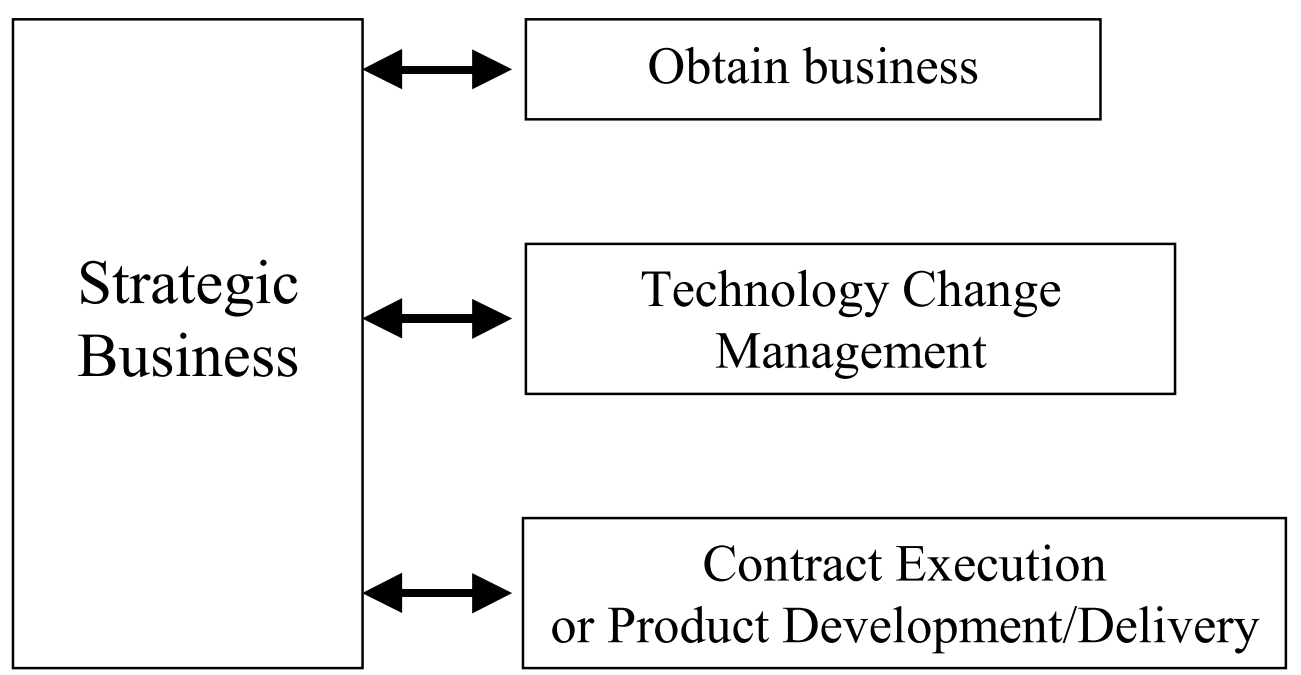

Figure 2: Strategic Planning/TCM Framework adapted from Litton-PRC

\subsubsection{Strategic Planning Observations}

- Both product technologies and infrastructure technologies contribute to strategic planning and obtaining business.

- A fundamental issue in product technology management is whether to buy companies who already provide the desired product technology or develop internal capability; both have advantages and disadvantages.

- Moving strategic planning from "closed" to "open" in terms of how strategic plans are communicated was a key factor cited in moving technology management into prominence within the organization.

- For organizations that are geographically distributed, publication and communication of the strategic plans is a key element in keeping corporate aligned with remote sites - no matter the context. This is a continuing challenge.

- A continuing issue for some organizations is "What is the right reach?" for the strategic plans? One high maturity organization cited a move from a plan with a 3-year scope and 1 -year centers to a plan with an 18-month scope and 6-month centers for the task planning as being more successful for them. 
- One way cited to obtain sufficient focus on technology management was to have the responsibility for technology change management be seated with the vice president of Engineering, through the Process Group as its home.

- Research and development of product line technologies as well as infrastructure technologies is seen as necessary scope for the technology change management processes.

- A "line of sight" from strategic plans through to individual objectives was necessary to make the alignment from strategic plans and business goals and organizational goals a reality.

- At least one annual offsite that brings together strategic business planning expertise with technology and product development expertise is necessary to keep the technology focus aligned with the business goals.

\subsubsection{TCM Improvements to SW-CMM v1.1}

The working group primarily has experience with SW-CMM v1.1, so this was the base used for discussions about potential improvements to the TCM key process area. The working group recognizes that some of these may have already been incorporated into SW-CMM Version 2 and the CMM Integration Framework. In parentheses after some comments is a suggestion of what element of the CMM might be the best place to address this comment. The abbreviations mean the following: $\mathrm{kp}=$ key practice, $\mathrm{sp}=$ subpractice, $\mathrm{ab}=\mathrm{ability}$ to perform common feature.

- Close coupling of strategic planning processes to TCM processes requires coverage. $(\mathrm{kp})$

- Emphasize "whole product" definition and development as part of TCM. (kp)

- Couple performance objectives to technologies planned for deployment (e.g., as whole product). (sp)

- Add coupling of proposing and implementing as strategy to get ownership. (ab)

- Bring "pilot teams" into planning and development of whole products. (kp)

- Address cultural implications of the definition of the scope of the whole product (e.g., multi-site, business context).

- Include direct addressing of "impacted areas" in technology/organizational analysis.

- Add more differentiation between "incremental" innovations" and "discontinuous innovations."

\subsubsection{Best Practice Recommendations for Successfully Deploying Technologies}

At the end of the working session, after looking at all the material generated, the working group had a discussion trying to summarize the most important things their organizations have done to successfully deploy technology. Some of these are repetitions of earlier points; others came from observing what we had done to answer other questions and from seeking for "what's missing." They are recorded here in hopes that they may provide useful insights to other organizations trying to improve their own organizations' ability to select and deploy worthwhile technologies. 
- selecting pilot teams based on technology adoption curve (early adopters preferred)

- "line of sight" coupling of technology objectives to organization and individual objectives, and budgeting and statusing

- separate group looking externally for "good matches" - NOT on project!

- widespread publication/briefing of tactical and strategic business and technology plans

- making the proposer the owner for implementation

- establishing technology architecture for SPI support early; deploying supporting technologies "just in time" with process deployment

- "stop the world" training for pilot teams and explicit coaching/mentoring

- mentor does NOT equal owner of the adoption (these are, however, complementary)

- increased sharing of technology deployment process with stakeholders throughout the TCM process...communicate...communicate

- adding mentors/coaches from process group and budget as "extra" staff to help pilots be successful

- establishing/employing feedback/refinement of whole product

- recognizing that first iteration does NOT equal the last iteration

- identifying the owner of the "sustaining" part of technology explicitly

\subsubsection{Recommendations for "TCM" Material Lower in SW-CMM}

One of the more provocative discussions within the working group was how technology adoption is and is not addressed within the SW-CMM. SuZ Garcia provided some background on the placement of technology-related material. She emphasized that the placement of technology-related material is focused on where in the organization's evolution "mastery" of technology issues is expected vs. at what point those issues would begin to be addressed. The group was not focused on moving the TCM KPA itself, but more on providing support in earlier parts of the model for providing enabling technology support for software practices, especially for software process improvement.

Members of one organization asserted that an emphasis on process-enabling technologies from the beginning of their SPI effort was a key to a rapid and consistent move from Level 1 to Level 5. Their analysis of the SW-CMM when they were first considering it as their improvement framework was that carefully deployed technology support would accelerate process discipline buy-in. They have coupled their technology strategy and their SPI strategy from the beginning of their SPI effort and have continued with this path throughout their effort. The identification of a technology architecture was provided with their initial SPI proposal to management, and the technologies were planned for and deployed in conjunction with their related process elements. This approach was different from the other high maturity organizations in the working group; however, the other organizations stated that they might have had an easier time at some points in their improvement efforts had they considered and employed this strategy. 
The primary suggestions provided by the working group are

- OPF should address integrating process architecture and technology support architecture

- Include more "feasibility" focus for technology_encouraging organizations to master analyzing the feasibility of different technology alternatives earlier.

- Feasibility focus might belong either as part of OPF or in the Ability to Perform section of different KPAs

- Focus on ROI for software process improvement within OPF - "start the way you mean to finish."

- Add subpractices/examples on appropriate technology support in relevant KPAs (e.g., problem report tracking, defect tracking).

- Add more front matter on technology implementation vs. TCM mastery.

- Emphasize appropriate "data collection" technology support at Level 2/3 and above as a way to reduce barriers to process deployment — where appropriate technology would help with process adoption, the lack of encouragement from the CMM can negatively impact organizations who are trying to follow the model closely.

\subsubsection{Summary}

Technology is an important element of product development and of process improvement. Selecting, using, and deploying it appropriately can make both product development and the improvement of product development easier and faster. However, making appropriate selections and deploying appropriately are the keys that are the issues of both low and high maturity organizations. High maturity organizations have better data on which to base technology decisions. However they still have challenges in appropriately deploying technology - the cultural and human behavioral issues that challenge lower maturity organizations still show up in higher maturity organizations. High maturity organizations employ differing strategies to address these issues; however, their common thread is tying technology use to business goals and involving the people who will be using technology in planning its deployment.

\subsection{Working Group 6: Human Issues}

Participants: Al Aldrich, Julie Barnard, Kelley Butler, Harry Carl, Bhaskar Chavali, Ellen George, Kelly Gunning, Barbara Kolkhorst, Judah Mogilensky (facilitator), L. Ravichandran, Sarala Ravishankar, Prabhuu Sinha, John M. Smith, Agapi Svolou, Carolyn Swanson, M. Thangarajan, Barbara Tyson

The overall topic of the working group was Human Issues in High Maturity Organizations. The general thrust of the group was to discuss these ideas and to record perspectives, but not to formally endorse any specific ideas or proposals as a group. 
The group began by collecting potential topics to discuss, and then conducting a multi-vote to identify those topics that the group was most interested in spending time on. The following is the list of potential topics that was collected; the highlighted topics were the ones that were chosen for discussion time:

1. buy-in, enthusiasm about process

2. cost, schedule, quality, ownership by developers

3. worker empowerment in process definition and improvement

4. worker empowerment through delegation of management authority

5. encouraging workers to report accurate data (defects, etc.)

6. sustaining enthusiasm in a growing organization

7. difficulties getting new staff and managers up to speed

8. neutralizing hot-shot cowboy developers

9. sustaining enthusiasm after hitting major process goals

10. how cultures (national, organizational, industry) impact process discipline and improvement

11. growing individual contributors in a team-oriented environment

12. tension between more process-oriented and less process-oriented projects and groups

13. how to motivate data collection from people who do not benefit directly

14. observed changes or evolution in interpersonal behavior patterns as organization matures

15. avoiding or managing dysfunctional behavior prompted by measurement

16. learning to build team chemistry

17. identification and development of core competencies

18. keeping people on large projects feeling important and significant

19. similarities and differences in people in people issues between lower maturity levels and higher

20. skeptics - how can we be high maturity if we are not perfect

The following sections summarize the discussion of the group regarding each of the highlighted topics. They are presented in the order in which they were discussed.

\subsubsection{Sustaining Enthusiasm after Hitting Major Process Goals}

Issue: How to sustain enthusiasm in process improvement after achieving major process goals. "Continuous improvement" does not have nearly the appeal of "getting a maturity level." (This is a particular issue for organizations that have achieved Level 5, and have no more maturity level goals to aim for.) 
Some of the methods offered to mitigate this issue were

- $\quad$ internal methods (things that can be done entirely within Level 4 and 5 organizations.)

- ISO 9000 registration and the required external audits every six months help maintain focus. (Because ISO registration requires regular re-validation, unlike CMM assessment results, the ISO re-validation exercises provide a means of keeping people in the organization focused on process issues.)

- ISO 9000-2000 will place increased focus on Statistical Process Control and Continuous Improvement. (This new focus will add Level 4 and Level 5 topics to the ISO registration and re-validation activities.)

- use of internal awards for teams. (Take focus away from improvement as measured by maturity levels, and put more emphasis on measuring and rewarding business results, now that the organization has the ability to do such measurement with reasonable accuracy.)

- Set a pattern of "set a goal," "achieve goal"" "set a new goal"- - eliminate the idea that process improvement is finished. (Always be prepared to set new performance goals, even if these do not involve new, higher maturity levels.)

- external methods (things that other organizations can do to help Level 4 and 5 organizations.)

- the SEI could require a re-validation of Level 5 assessments every five years. (For the first time, the SEI could establish renewal requirements for CMM-based maturity level ratings. Initially, this idea would be applied only to Level 5 organizations, and only at five-year intervals. Later, renewal requirements could potentially be considered for other maturity ratings.)

- DoD requirements for SEI CMM Levels and assessment recency. (Many DoD procurements that require submission of maturity level data also require that the assessment or evaluation not be more than so many months or years old. This requirement can prompt organizations to conduct re-assessments after a period of time, even though there no expectation of a higher rating than the Level 4 or Level 5 achieved last time.)

- requirements for more public sharing of ROI data and benefits, like for the Baldrige and the IEEE awards. (Creating a culture in the CMM community that organizations achieving Levels 4 and 5 are expected to report, at least once but perhaps regularly, on their performance and on the measured benefits of their maturity levels.)

\subsubsection{Encouraging Workers to Report Accurate Data}

Issues

- In some cases, workers resist data reporting. Why? How can managers overcome this resistance?

- There is a tradeoff between data accuracy and data cost. How can managers strike the right balance? 


\subsubsection{Resistance to Data Reporting:}

Timekeeping: Detailed timekeeping is essential to quantitative process management. However, many managers don't realize how much of their time (or, how little of their time) workers spend on their work products. This time, known as yield or duty factor, is often a small percentage of the typical workweek. In fact, $50 \%$ yield is usually considered good, and $60 \%$ is considered a phenomenal yield. Lower-maturity organizations usually don't collect enough data to determine yield, so workers face a significant issue when asked to start detailed timekeeping:

"I know how little time I spend on my work products and planned tasks during the week, and how much time I spend in meetings, answering management questions, and taking care of the unforeseen (personal and work-related). Management has no clue about how I spend my time. What happens to me when they find out?"

There are at least two keys to resolving this issue:

- Managers need to get past their surprise at the timekeeping data, and investigate the reasons yield is lower than expected. With accurate timekeeping data, managers can start fact-based process improvement. This improvement works on two levels: first, the organization gets a better process; second, workers can see managers using the data for improvement, not unfair retribution against workers. This helps everyone understand how data empowers the organization to improve.

- Managers must understand that being human is a legitimate workplace activity. Workers need to talk, and not always about work. Workers have lives outside work, and there are times when life preempts work. Managers must let their people know that these human activities are an acceptable and expected part of life in the workplace.

Defect Reporting: There is a natural tendency for workers to avoid reporting their own de-

fects. Here are some key points:

- Managers need to show workers - by example - how to use defect data to improve processes.

- Managers must avoid using defect data for individual retribution, so fear is driven out. (A point that was often stressed by W. Edwards Demming.)

- Defining "defect" is critical. Some organizations don't consider unit test errors to be defects, but others do. Some organizations don't count defects until peer review of unit test results. PSP counts compile errors as defects. There is no clear consensus, and managers need to carefully evaluate the tradeoffs based on their business needs and software processes.

- Some organizations use independent testers from unit test through final delivery to help ensure accurate defect reporting.

- Some organizations make reported defect quantity a key metric for each individual, though they also include other measurements to help ensure the defect reporting isn't inflated. Control charts of defect data also highlight under-reporting of defects. 
- Defect data collected by organizations represented in the group included defect density at delivery and "leak-through," i.e., defects injected in one phase, but detected during a later phase.

\subsubsection{Balancing Data Accuracy and Data Cost}

The discussion then returned to the timekeeping topic. Accurate timekeeping data is essential. However, most organizations find it easier to collect effort data for process management separate from their accounting and payroll systems. The duplicate data entry costs less than the effort and time required to get required process data from the accounting and payroll systems. Accounting and payroll systems focus on data required to pay employees and bill customers, not data required to manage processes. It is usually more effective to use a separate system for recording total time spent on all activities, so the time can be categorized by project, phase, activity, or other required category.

If task effort is different from paid effort - as is often the case when workers are salariedthere can be complications from US Labor Department definitions of hourly and salaried employees, and rules governing their treatment.

Most organizations automate data collection and analysis because it helps maintain accuracy, reduces delays, and improves efficiency. However, it is important to maintain support staff for the timekeeping and data collection systems. Cutting support staff to reduce costs doesn't make sense unless data collection is also reduced, thereby reducing process effectiveness. Someone must still collect data, and if there is no support staff, then higher-paid professional staff must do the work. (Shifting work from lower-paid support staff to higher-paid professional staff does not seem to be a way to achieve cost savings, but organizations seem to try it all the time.)

There is a natural link between task effort, task results, and earned value. If effort data is collected separately from accounting and payroll data, the effort data can drive the earned value system. The accounting and payroll data generally cannot be used for earned value, because those data do not reflect the total task effort, e.g., if technical people are salaried or work uncompensated time.

\subsubsection{Notes Regarding PSP Implementation}

One of the organizations represented in the Human Issues group had implemented PSP over a year ago. Here are some relevant points from that experience:

- Managers were very surprised by initial yields averaging 9 hours per week (out of a nominal 40 work hours per week, only 9 were actually spent doing real project work). Once managers attacked the underlying process problems, yield improved until it reached 15 hours per week one year later. 
- The organization developed a tool for individuals to track time very precisely. When a worker starts a planned task, the worker starts a timer on the workstation screen. When work stops for any reason, the worker stops the timer. (Operation of the tool is similar to a "chess clock.")

- The task timer tool made the impact of interruptions obvious, and created demand for better time management. Since management was considered a primary source of interruptions, management designated each morning for "quiet time:" no phone calls returned, no meetings, and no email read or answered. This contributed significantly to improved yield. (In a similar vein, some organizations have tried designating one day per week as a "meeting-free day," again to increase time on task.)

\subsubsection{Avoiding or Managing Dysfunctional Behavior Prompted by Measurement}

Issue: The act of measurement can engender dysfunctional behavior, i.e., focus on what is measured to the neglect of non-measured duties of equal importance/criticality. (This argument is made very effectively in the book Measuring and Managing Performance in Organizations by Robert D. Austin, Dorset House Publishing, 1996.)

Some of the ways to mitigate this issue are

- Be aware/sensitive the impact of data can have on individuals (see issue statement above).

- Understand that being human and doing human activities is legitimate, i.e., human activities must be allowed.

- Understand that an "on-task" percent of work time of 50\% is VERY good; most of the remainder is taken up with management required tasks; only a little is taken up with "being human" tasks.

- Don't use process data/metrics results to reward or punish individuals.

- According to Deming, teams, not individuals, should be rewarded. For example, one organization's members described their reward breakdown as follows: $30 \%$ based on achieving individual goals, $40 \%$ based on team goals, and $30 \%$ based on the organization's goals.

- Understand and differentiate between measures used to reward a team for project execution vs. measures used as a basis for hiring, firing, promotion of individuals

- Take the time to make what some people view as "scary" measurements as "okay" within the organization, i.e., acceptable and normal in the organization's culture. Plan for the fact that some measurements will take a "long" time to establish.

- Use data to remove people from a project, NOT from the organization. This movement, in cases where unsuccessful managers were returned to engineering duties, worked out well for the individuals, i.e., they were happier after the change.

- Use mentoring and coaching to discuss where obstacles are and determine what help individuals/teams need to succeed.

- One approach used is to perform a skills review at different project milestones instead of one time only. (That is, at each milestone, review the skills required for the 
next pieces of work vs. skills present on the team, and take action as needed. This is contrasted with performing a skills review once, at the start of a project, and then never re-visiting it.)

- Many program managers (PMs) don't really understand what it takes to develop software. You must help the PMs and other managers gain a more holistic view of software development. They must understand what skills and knowledge are needed for each individual to perform.

- Change manager's role (e.g., the SEPG's role) to include the creation of a culture that accepts metrics and their use as acceptable and beneficial.

Example 1 of what worked for one organization is described below:

- The organization had evolved a culture where is was not "okay" to ask for help, so junior people spent a long time struggling with problems even though mentors were available to help them. To address this problem, everyone was given a red, yellow, green balloon. When a problem arose the person lowered the green balloon and raised the yellow. If the person could not solve the problem in a specified reasonable time, the yellow was replaced with a red balloon. Mentors were always available to identify and work problems, and they would watch the balloons, so they would know where to go. This approach worked well in a "bay" like environment where the balloons can be easily seen over cubicle walls. The approach was clearly acceptable in this organization, and it created an "okay" way to ask for help.

Example 2 of what worked follows:

- Organization established a firm policy of NOT accounting for non-task hours, and only tracking on-task activities, and allowing for the addition of non-planned tasks. The concern was to avoid the impression of a "big brother watching."

- People were given the task of developing their own task plan for improving selected measures. Based on their own recorded data, they determined if they had met their task plan, and they would take corrective action or not, as warranted. This was all done privately by individuals, so there was no management imposed visibility, yet normal competitive peer pressure can't be hidden so everyone strives to do better.

An alternative view of the strategy employed in Example 2, as implemented by another organization: Time tracking codes were established for some non-tasks hours, e.g. meetings, briefing, training, etc. This organization felt that tracking measures for some non-task hours was both acceptable to the workers and provided useful data.

\subsubsection{Tension Between More Process-Oriented And Less Process-Oriented Groups And Projects}

Issue: While most projects in high maturity organizations demonstrate a very high commitment to processes, there may be a few projects that do not display the same enthusiasm for processes. This "backward" behavior by one or two projects leads others to question why they are working so hard to follow process. Similarly, the software group may be following 
processes, but the other groups like hardware, etc., may not have rigorous processes. This again leads to questions like "Why just us, but not hardware, others ?" This invariably causes tension between more process-oriented and less process-oriented groups and projects.

During the group discussions, it emerged that this issue is typically faced when an organization is experiencing a large growth, because of customer resistance to process adherence, or because of rapid technology change.

- Large or rapid growth leads to major assimilation challenges, resulting in varying degrees of process institutionalization. As process internalization and ownership is not uniform across the organization, it becomes easier for small projects to become the first ones to adhere to processes, and for larger projects to lag behind. In such situations, the problem tends to go away with time, implying that the issue is a characteristic of rollout, but not of later phases.

- Some projects may become laggards because of customer resistance to process, as the customers communicate that "Level 3 is all I need, I won't pay for more than that" or "ISO is a resource drain." In such cases, customer education is important, and organizations have to convey to the customer that it will cost the customer more to do it "the customer's way," which has had the desired result. (This is an instance of the process improvement theme of "putting customers in touch with the consequences of their own actions.")

- When new technology is adopted, the projects have a tendency to believe that the "old" process does not apply to their project. (Depending on the situation, there may be some legitimacy to this claim. However, that becomes an argument to update the process, not abandon it.)

Because of the varying nature of individuals in an organization, there will be pockets of laggards who will resist any change. It appears that many laggards do catch up over time, and the issue goes away. However, there are some laggards who never catch up, who then become "second class citizens" and impede the work of the rest of the organization. It now becomes a management challenge to deal with such situations effectively. Managers and customers need to have the right data to take correct decisions.

At the end of the discussion, the myth regarding the "conflict" between creativity and discipline was explored. Many staff believe that processes tend to stifle creativity. The example of artists who spend a long time learning the discipline of their art before becoming creative in their fields was discussed, i.e., it is the discipline that enables and leads to creativity.

\subsubsection{Similarities and Differences in People Issues between Lower and Higher Maturity Levels}

Issue: What are the major similarities in the people issues between lower and higher maturity levels, that is, what issues tend to persist without significant change as the organization progresses? And, what are the key differences in the people issues between lower and higher 
maturity levels, that is, what issues tend to go away at higher levels, or only emerge at higher levels?

It was the consensus of the group, after discussion, that there are behavioral clues that are indicative of the maturity level of the organization. That is, organizations of different maturity levels behave differently. The following ideas were developed:

There are differences:

- Buy-in is a continuous process. But buying in to CMM SW Levels 2 and 3 does not automatically lead to buy in for Levels 4 and 5. Re-contracting with the organization is needed each time to convince the members and managers of the value of the improved level. At higher levels, members of the organization can see the values of earlier practices and buy-in tends to deepen.

- At the early levels, there is the introduction of discipline where perhaps none had existed before; at the higher levels the organization must add and refine the existing discipline.

- There is a shift in motivation at higher levels. The organization moves from escaping pain (e.g., failed projects, lost contracts, lost customers, etc.) to seeking improvement opportunities. (This is a challenge to management, driving change from a basis of seeing how things could be better, even though they are okay now, as opposed to driving change from a basis of avoiding visible and obvious bad outcomes.)

- Understanding and commitment are deeper at the higher levels. Compliance and rote following of processes that are not well understood can work at lower levels, but employees need internalization and understanding for higher levels to be achieved.

\section{There are similarities:}

- There is no change in who must buy in. All types of people must buy in at each level: the staff to report and analyze data and the managers to use the data properly.

- Process maturity does not always equal emotional maturity. There are defensiveness, posturing, and politics at all levels.

- Humans often choose the familiar and comfortable over the unknown. (This can be true at all levels.)

- Development of and conformance to process is an evaluation factor for everyone in the organization.

\subsection{Working Group 8: Software Quality Assurance}

Participants: Dottie Acton, Colin Benton, Rick Biehl, Russ Campbell, Joe Puffer, Prathima Srinath, Warren Schwomeyer 


\subsubsection{Discussion Framework}

This paper presents the results of the working group on Software Quality Assurance. The working group looked at the multiple ways in which the SQA role changes as an organization matures, and on the impact of those changes on the organization and on the individuals within the SQA group.

The discussion of the working group was framed around a two dimensional framework; one dimension being the five successive maturity levels of the CMM, and the second dimension being the topics of inquiry being discussed by the group. These topics included

- Independence to Objectivity - The extent to which the independence of the SQA group within the organizational structure influences the objectivity - real or perceived - they bring to bear on their activities.

- Organizational Resistance - The extent to which the organization resists the role and function of SQA as the processes of the organization mature.

- Customer Integration - The extent to which the customer can be integrated as a natural partner in the SQA process.

- Push to Pull - The extent to which the SQA dynamic shifts through maturity from the SQA organization pushing itself onto the project arena, to the project environment pulling the SQA function in.

- Assurance Target - The extent to which the target of SQA activities shifts from simple standards compliance toward more effective improvement strategies as maturity progresses.

- Skill Requirements - The extent to which the skills required of the SQA function change as maturity levels are progressed.

- Roles and Responsibilities - The extent to which the expectations for roles and responsibilities associated with SQA shift as maturity progresses.

- People Impact - The extent to which SQA affects the career paths and opportunities of its practitioners in differing ways as maturity progresses.

Discussion progressed from topic to topic, identifying and noting the characteristics and behaviors of the discussion area as it progresses through the maturity model. This provided a vehicle for understanding the SQA transition from each distinct perspective.

\subsubsection{Observations}

Results of each of the specific discussion topics are detailed below.

\subsubsection{Independence to Objectivity}

Summary: In a Level 1 organization, personal contact by SQA provides visibility into the project activities. Since this is the case, there is a tendency to equate independence with objectivity, since the separation gives the freedom to make less than popular decisions. At Level 2, the project's documented processes provide a framework for the SQA visibility. At 
Level 3, SQA is more integrated with the teams and can begin to use data to provide visibility into the project status. At Level 4, the detailed data that is available provides the objectivity needed, even without organizational independence. At Level 5, the process itself provides inherent objectivity, and SQA can step back and observe at a higher level.

The CMM suggests that the SQA group has an independent reporting channel to senior management and that this independence should result in confidence that objective information is being reported.

There are two elements to be considered in tracking the maturing of the implementation of the SQA function from Level 1 to Level 5. Visibility of the SQA group into the process and product quality is the first element. This relates to how information upon which assessments are based is obtained. The second element is Objectivity. This element relates to how the reporting objectivity is ensured.

At Level 1, the SQA function may not even be performed. When it is performed, visibility is obtained through personal contact. SQA representatives are present at all inspections, at prescribed levels of testing, at all status meetings, etc. SQA obtains the needed information by being present when it is being generated and observing it first hand. At this level, the organizational independence is equated with objectivity. The SQA group reports through an independent channel, therefore its reporting "must" be objective. This independence also produces an SQA group that is separate from the development group. An "us vs. them" perspective often develops between the two groups, which enhances the perceived objectivity.

The project's defined processes provide visibility at Level 2. Each project's processes are defined and documented in advance. This allows the SQA group to "see" what is going to happen on the project and develop an SQA Plan that begins to select the areas for SQA oversight. The project planning performed at Level 2 provides objective expectations for the whole team, including SQA. The defined processes and project plans establish a phased approach to the project presenting SQA with differing opportunities for assessment and review in each phase. At this level, SQA is starting to be viewed as a member of the team.

SQA becomes a full member of the team with the establishment of Integrated Product Teams at Level 3. Improved data collection, analysis and retention (e.g., central repository) provide improved visibility and objectivity at Level 3 . The granularity of information available increases the opportunities for a wider array of assurance activity and involvement with the project. The data begins to "speak for itself."

Level 4 performance provides more detailed data and more mature analysis techniques. Objectivity results from listening to what the data says about process and product quality. 
Self-initiated, continuously improving processes contain inherent objectivity at Level 5. At this level, SQA can step back from the process and observe. Visibility is achieved through sampling and selective involvement. Observation of perturbations in a well-running process provides SQA's impetus for action.

SQA changes along with the software development process in a maturing organization. The means by which SQA obtains visibility into the process and product quality transitions from being additional activities to being integrated activities to being observational activities with negligible disruption to the basic software development and management activity. The understanding of objectivity changes, allowing a maturing organization more flexibility in implementing the SQA function. The organization relies less on organizational independence and more on data objectivity.

\subsubsection{Organizational Resistance}

Summary: In a Level 1 organization, there is overt resistance to SQA, both because of the perception that SQA costs too much, and the confrontational nature of the police activities that SQA is forced to perform. At Level 2, and 3 this abates somewhat with the cultural change that accepts the SQA role as part of the process; however covert resistance is sometimes present. It isn't until Level 4 that most projects will have the detailed data that can allow them to understand the value of QA. At Level 5, with the focus on improving the process, the relationship with SQA becomes one of collaboration and encouragement rather than confrontation.

At Levels 1 and 2, SQA is forced on projects that typically do a poor job of estimating. Consequently, SQA exacerbates their cost and schedule overruns. Customers are unwilling to pay for SQA because, in their view, the developers should take care of quality as a matter of engineering excellence. Projects are also unwilling to pay for SQA which provides little in the way of useful service or feedback.

Rules get in the way of progress and entrepreneurial project management, resulting in project confrontation. Finger pointing occurs along with 'in your face' audits. The evaluators who typically have poor software engineering skills cause friction when finding product errors. Typical defects found by SQA are superficial, cause lots of paperwork, and aren't always reported fairly. SQA is not usually a partner before Level 3. Overt resistance is typical, with an "us vs. them" attitude prevailing. SQA is not invited to many activities.

A culture change occurs on the way to Level 3. There is an acceptance of SQA's role, and it becomes part of the formal development process. As IPTs form, SQA is included from the beginning. The instantiation of peer reviews along with product diversity causes SQA to take on a process auditing role. SQA begins to use the science of sampling to assure coverage with a small staff. However, the organization is increasingly heterogeneous with projects at all levels of maturity. The SQA function must interface with these projects, and provide the 
proper support. Friction and organizational resistance occur with the lower maturity level projects, and when a Level 1 auditor works on a project exhibiting Level 3 maturity.

It is only as the organization implements Level 4 practices, that there is enough data to understand the value of SQA. Organizational resistance disappears as the data captures the cost of quality, and the value proposition for having SQA functions is articulated. SQA loses the process and product police stigma. They are watching quality through organizational data, which removes them from confrontational situations. SQA actively works defect prevention issues along with the developers, which reinforces the idea of partnership. While heterogeneity of service increases, the SQA management is able to use data to provide appropriate service at all maturity levels without invoking resistance.

The organization works with the QA function in a collaborative manner at Level 5. SQA is encouraged to assist with process management and technology problems encountered on the projects. The SQA mentoring function at Level 5 overcomes any resistance that might be left.

\subsubsection{Customer Integration}

Summary: In a Level 1 organization, SQA is often performing in the role of the eyes and ears of the customer, with a focus on ensuring that customers get the product that they expect. At Level 2, SQA begins to monitor the state of the process as well as the product, still serving as the eyes and ears of the customer, but with earlier opportunities for feedback. At Level 3, usually a change occurs with the introduction of IPTs that include the customer. At this point, there is less value in the SQA role as a customer surrogate since the customer is involved in the process.

At Level 1, SQA serves as the eyes and ears of the customer. The customer is primarily interested in the product being produced, and has to be strongly encouraged to show interest in the process being used by the project. SQA often provides the only visibility the customer can get to product quality. As maturity progresses toward Level 2, the customer begins to care more about the process, but still doesn't typically become a participating stakeholder in the process.

By Level 3, customers are more involved in the process; often through participation in IPTs. Customers are no longer outside observers to the process; rather they are participating in process activities directly and are often taking responsibility for their own actions in the plan. SQA is still participating, but tends to take more objective positions on the team as customers take responsibility for their own interests.

As projects approach Level 4 maturity, customers have gained enough confidence in the process to begin taking greater risks, including participating in process-based incentive plans and increased customer project ownership. By Level 5, customers see the process as an opportunity for mutual improvement and the sharing of opportunities identified by any stakeholder. 
The line between customer and provider is not clearly evident in the process, reducing the need for SQA to serve as customer surrogate.

\subsubsection{Push to Pull}

Summary: In a Level 1 or 2 organization, SQA is frequently only present on a project because it is required, either by the customer or by organization policy. At the higher levels, SQA is usually present on a program from the beginning, as an integral part of the program team.

At Level 1 the organization lacks management practices and has different objectives. Occasionally, managers impose a systematic approach to software development and maintenance, but resort to shortcuts during crisis. In some cases, ad hoc practices may be enforced. They are normally reactive measures. Generally, at this level, quality assurance is customer focused and largely pushed onto projects.

During institutionalization of management practices, defined practices are implemented by projects because the products and activities are reviewed, audited and reported. They include SQA because it is required. As maturity improves, organizational push for disciplined approach is much more evident than customer push. The organization as a whole sets the policies to implement management practices and ensure compliance.

At higher maturity levels, service is context dependent. Customer participation in product and process reviews is planned. The SQA group and customer representative are part of project and are involved with the project from initiation and planning stage to establishment of plans, standards, and procedures. Activities are performed according to the plan. SQA provides visibility on process compliance, and sees itself further pulled into the process.

At Level 4, quantitative measures are adopted to track and control the project and the process. This empowers each project to manage based on actual data. Management and control is driven by organizational assets. By Level 5, SQA has been pulled completely into the process as an integral part from the beginning. The systematic approach is inherent in software development and maintenance activities. It is no longer customer driven or organization driven. Quality assurance is built into project requirement.

\subsubsection{Assurance Target}

Summary: At Level 1, the SQA focus is on standards compliance, usually after the fact. In essence, SQA is asking "did you produce the correct product?" At Level 2, it becomes possible for SQA to verify in-process compliance, and to ask "are you following the steps needed to produce a quality product?" At Level 3, this in-process compliance activity increases, especially with the introduction of inspections. At Level 4, SQA is able to challenge the organization by asking if the metrics show "can you get there?" As the project teams begin to control their processes to manageable targets, SQA can also ask "will you get there?" At Level 5, SQA becomes an integral part of the process and product improvement activities. 
At Level 1, SQA focuses on standards compliance, usually after the fact on projects. In many Level 1 organizations, a general absence of standards results in SQA activities centered around industry norms and conventions. SQA is typically asking if the projects have done what was expected; a strictly reactive mode.

By Level 2, enough process has been defined for SQA to begin actions based on in-process compliance. SQA impact can be immediate, but is still largely reactive because of a continuing lack of visibility into the detail processes. As visibility increases at Level 3, SQA can have more immediate impact; challenging projects as they progress. The introduction of more systematic reviews and inspections shifts more of the SQA focus to the project teams. The shift of SQA staff from reactivity toward future planning takes place during this period.

By Level 4, challenge has turned to control; as SQA becomes able to monitor manageable targets and the projects take on more and more of the SQA responsibility embedded in their plans. SQA focuses on future planning with projects; assuring that projects will be able to work toward their own quality goals. By Level 5, SQA focus is exclusively on process and product improvement, with project appraisal and conformance issues completely shifted to the project teams.

\subsubsection{Skill Requirements}

Summary: At Level 1, members of the SQA organization need to be detail-oriented, with strong audit skills. At Level 2, the skill requirements increase to include basic metrics skills and software skills. With the progression to Level 3, there is a need for facilitation skills, process improvement skills, and more advanced metrics and analysis skills. At Level 4, consulting skills are needed, as is increased depth and breadth in software skills. Level 5 adds more, including defect prevention and causal analysis, mentoring and advanced modeling skills.

At Level 1, members of SQA need to be very detail-oriented; with strong audit and coordination skills as they deal with almost exclusively low maturity project behaviors. As maturity levels increase, SQA staff will need to take on the knowledge implied by the improvement process areas; often leading such learning in the organization, while offering support to others working on similar learning curves.

As the organization progresses to Level 2, SQA people must improve their basic metric skills; as well as overall software project and engineering knowledge. Their coordination skills must expand into facilitation; being able to inform and guide projects toward process improvement.

By Level 3, SQA staff must have the more advanced metrics and analysis skills needed to help the organization and projects benefit from early metrics. Such successes are key factors in building support for continuing the improvement initiatives. Facilitation skills expand 
here into a broader consulting skill set as SQA staff work with more people in the organization.

As the focus of improvement becomes more targeted toward Level 4, SQA staff must maintain their knowledge base in software and software engineering in order to be able to participate in the discussions that will surround early defect-analysis activities. That knowledge, supported by skills in defect and causal analysis will make the SQA a valued resource to these higher maturity projects.

By Level 5, SQA staff require the ability to mentor others on the staff, guiding them along the same learning path that the SQA staff member has followed. In addition to analysis skills, the SQA member must develop skills in general modeling as higher maturity improved metrics become available requiring such analysis. SQA staff will need to maintain all of these levels of skill simultaneously in order to continue to support the broad range of projects encountered in such high maturity organizations.

\subsubsection{Roles and Responsibilities}

Summary: At Level 1, SQA responsibilities are frequently limited to reactive, after-the-fact reporting. At Level 2, this changes to a stop-the-line mentality, as in-process problems are detected. SQA performs its activities through attendance at meetings and through direct oversight of program and subcontractor activities. At Level 3, they are more involved with project activities such as inspections, and can provide more current reporting of project success or issues. At Level 4, a significant change takes place since they can now use sampling to obtain data, and can provide before-the-event projective reporting. At Level 5, this can progress to being able to provide an organizational as well as project viewpoint to management.

At Level 1 the role of SQA is one of policing the software development project. SQA is responsible for reporting typically to the project customer how well the project has met contractual requirements. Reporting is after the fact which leads to a reactive, disjointed relationship between the project and SQA. The focus of SQA is on project completeness.

As a project moves to Level 2, SQA continues in the policing role. Members of SQA typically attend reviews, inspections, and status meetings. Reporting is still typically after the fact with a "stop the line" mentality. SQA findings are written and dispositioned before the project can complete.

SQA in a Level 3 organization takes on a more proactive role of directly monitoring the project activities and work products. Reporting of process execution and product quality occurs concurrently with the development. The focus is on project success.

As an organization moves to Level 4 the role of SQA becomes one of indirectly monitoring the project activities and products. The engineering group accomplishes many quality assur- 
ance activities. SQA monitors the accomplishment of activities such as inspections and reviews. Sampling of process results and product quality is performed.

An organization operating at Level 5 will be implementing processes that watch themselves through the continuous collection and analysis of data. The SQA role is one of projecting the project outcome based on the processes, technologies, and resources in place. Reports are provided to management and the team members before events occur to ensure a successful project. The focus is on organization success.

\subsubsection{People Impact}

Summary: At Level 1, SQA is seen as a limited career path, for individuals with fewer skills. As the organization matures, they must gain the vision of where the organization is going, and begin to look ahead to the next steps in the process for the project. By the time the organization and SQA reach Level 5 maturity, SQA is seen as a leader - the choice career path for the best the organization has to offer.

SQA is seen as a very limited career path at Level 1. It is often presumed to be a side-track assignment or individuals with fewer skills. Many SQA people in low maturity organizations see themselves as being "punished" in some way; often after having excelled as project leaders.

As the organization matures through Levels 2 and 3, SQA people must gain the vision of where the organization is going, and begin to look ahead to the next steps in the process for the project. They must become active participants in the planning and management side of process maturity. They can't spend all of their time in trenches with the projects unless they desire to rotate back to direct project assignments shortly. As a path into management, SQA requires a broader participation and visibility across the entire organization.

As the organization and SQA progress through Level 4 to Level 5, SQA is seen as a leader in process improvement specifically, and the organization generally. SQA represents a viable and preferred career path for the best the organization has to offer. 


\section{Considerations for Next Steps}

The High Maturity Workshop was favorably reviewed by the participants, as was the survey of high maturity organizations. In the workshop evaluation, $56 \%$ of the participants suggested the workshop should be an annual event, and the rest preferred an 18-24 month cycle. As part of the SEI's ongoing communications with this segment of the Software CMM user community, it is our intent to make both the workshop and the survey regular events, occurring on a roughly annual cycle.

Although the high maturity segment of the software community is growing rapidly, there is some question about what "high maturity" really means. The Software CMM does not have as complete a picture of Levels 4 and 5 as is captured for Levels 2 and 3, thus the opportunity for high maturity organizations to discuss directly the issues and challenges they have to deal with provides a valuable dialog for both the companies and the SEI.

There is reason to believe that some organizations have taken an overly liberal interpretation of Levels 4 and 5 in the Software CMM. This is similar to the situation in 1990, when significant consistency and reliability issues with Level 2 and 3 assessments were reported. This was a particular concern for organizations pursuing government contracts where the results of software capability evaluations against the SEI maturity framework of that time were a factor in source selection. The most significant step in addressing this problem was the publication of Software CMM v1.0 in 1991, which provided a comprehensive description of Levels 2 and 3.

The current release of the Software CMM, Version 1.1, was released in 1993. A conservative stance was taken in defining Maturity Levels 4 and 5 because of the sparsity of Level 4 and 5 organizations. We have learned much about high maturity practices since then, through mechanisms such as the high maturity workshops, but the fundamental principles of Levels 4 and 5 are not as clearly articulated in Version 1.1 as we might wish. The planned release of Software CMM v2 in 1997 was halted in favor of work on CMM Integration. Drafts of the CMMI model are available at http://www.sei.cmu.edu/ $\mathrm{cmm} / \mathrm{cmms} / \mathrm{cmms}$.integration.html and incorporate much of the current thinking on Level 4 and 5 practices, but the operational model today remains Software CMM v1.1 as released seven years ago.

The SEI is taking steps via papers, training, and other mechanisms to address this problem. SEI training on high maturity practices and statistical process control for software is now available, but it will take time to deploy these courses to the software process improvement community and the Lead Assessors. Work continues on understanding high maturity prac- 
tices better through the workshops and surveys, and it is hoped that better communication between the high maturity organizations and Lead Assessors will clarify many of the high maturity challenges that the software community faces.

The issues surrounding quantitative management - including both measurement and statistical process control - are challenges even for high maturity organizations. Even the growing use of control charts as a standard part of the software process should not suggest that they become a requirement for high maturity. There are still unanswered questions regarding the business value of various quantitative management techniques in different business environments and in conjunction with different software engineering methodologies. For example, most high maturity organizations today are in high reliability environments, building realtime applications and/or embedded systems [Paulk 00]. Will control charts provide significant business value in a commercial shrink-wrap environment? Conceptually, Levels 4 and 5 of the Software CMM are based on stable and capable processes as traditionally controlled by SPC. Empirically, we are still exploring the implications of these concepts in a designintensive, human-centered process. 


\section{References}

[Billings 94] Billings, C.; Clifton J.; Kolkhorst, B.; Lee, E. \& Wingert, W.B. "Journey to a Mature Software Process.” IBM Systems Journal 33, 1 (1994): 46-61.

[Butler 95] Butler, Kelley L. "The Economic Benefits of Software Process Improvement." Crosstalk: The Journal of Defense Software Engineering 8, 7 (July 1995): 14-17.

[Butler 97] Butler, Kelley. "Process Lessons Learned While Reaching Level 4." Crosstalk: The Journal of Defense Software Engineering 10, 5 (May 1997): 4-8.

[Cosgriff 99a] Cosgriff, Patrick W. "The Right Things for the Right Reasons: Lessons Learned Achieving CMM Level 5." Crosstalk: The Journal of Defense Software Engineering 12, 5 (May 1999): 16-20.

[Cosgriff 99b] Cosgriff, Patrick W. "The Journey to CMM Level 5: A Time Line.” Crosstalk: The Journal of Defense Software Engineering 12, 5 (May 1999): 5-6, 30.

[Craig 99]

Craig, Rushby "Software Quality Assurance in a CMM Level 5 Organization." Crosstalk: The Journal of Defense Software Engineering 12, 5 (May 1999): 1115.

[Ferrara 00] Ferrara, Linda \& Timko, Cathy. "The Telcordia Technologies Road to Quality." Cutter IT Journal 13, 2 (February 2000): 28-34.

[Fishman 97] Fishman, Charles "They Write the Right Stuff," Fast Company (December/January 1997): 2-7.

[Forrester 99] Forrester, Eileen; Fowler, Priscilla \& Guenterberg, Sharon. "The Managing Software Innovation and Technology Change Workshop." Crosstalk: The Journal of Defense Software Engineering 12,11 (November 1999): 22. Available WWW <URL: http://www.stsc.hill.af.mil/Crosstalk/>.

[Fowler 97] Fowler, Kimsey M. Jr. “SEI CMM Level 5: A Practitioner's Perspective." Crosstalk: The Journal of Defense Software Engineering 10, 9 (Sept 1997).

[Krasner 94] Krasner, Herb, Pyles, Jerry \& Wohlwend, Harvey. A Case History of the Space Shuttle Onboard Systems Project. SEMATECH, Technology Transfer 
(94092551A-TR). October 31, 1994.

[Levine 99] Levine, Linda. "Introducing New Technology Rollout Product Description." Crosstalk: The Journal of Defense Software Engineering 12, 11 (November 1999): 17-21.

[Miller 98] Miller, Corinne. "Sustaining a Continuous Improvement Culture: From Start-Up Venture to Big Business in a Decentralized Culture." Proceedings of the 1998 Software Engineering Process Group (SEPG) Conference. Chicago, Il. March 9$12,1998$.

[Moore 91] Moore, Geoffrey A. Crossing the Chasm: Marketing and Selling High-Tech Products to Mainstream Customers. New York, N.Y.: HarperCollins Publishers, 1991.

[Oldham 99] Oldham, Leon G.; Putman, David B.; Peterson, Mark; Rudd, Bruce \& Tjoland, Kevin. "Benefits Realized from Climbing the CMM Ladder." Crosstalk: The Journal of Defense Software Engineering 12, 5 (May 1999): 7-10.

[Paulk 95] Paulk, Mark C.; Weber, Charles V.; Curtis, Bill \& Chrissis, Mary Beth. The Capability Maturity Model: Guidelines for Improving the Software Process. ISBN 0-201-54664-7, Reading, Ma.: Addison-Wesley Publishing Company, 1995.

[Paulk 99] Paulk, Mark C. \& Putman, David. "Assessing a Level 5 Organization." Crosstalk: The Journal of Defense Software Engineering 12, 5 (May 1999) 2127.

[Paulk 00] Paulk, Mark C.; Goldenson, Dennis \& White, David M. "The 1999 Survey of High Maturity Organizations.”(CMU/SEI-2000-SR-002) Pittsburgh, Pa.: The Software Engineering Institute, Carnegie Mellon University, February 2000.

[Ravishankar 99] Ravishankar, Sarala; Sankaran, Prashant; Chitnis, Sanjay \& Sampath, Anand "Practices of a CMM Level 5 Organization," The SEPG Conference in India. Bangalore, India, February 24-25, 1999.

[Wigle 97] Wigle, Gary B. \& Yamamura, George. "Practices of an SEI CMM Level 5 SEPG" Crosstalk: The Journal of Defense Software Engineering 10, 11 (November 1997): 19-22.

[Yamamura 97] Yamamura, George \& Wigle, Gary B. "SEI CMM Level 5: For the Right Reasons." Crosstalk: The Journal of Defense Software Engineering 10, 8, (August 1997): 3-6. 


\section{Appendix A: List of Workshop Participants}

Dorothy Acton, Lockheed Martin Mission Systems, Gaithersburg, MD

Armistead Aldrich, Lockheed Martin Mission Systems, Gaithersburg, MD

Mark Amaya, SPP\&T, El Toro, CA

Paul Andersen, NCR Corporation, San Diego, CA

Julie Barnard, United Space Alliance, Houston, TX

Colin Benton, Alenia Marconi Systems, Cambradley, United Kingdom

Richard Biehl, Data-Oriented Quality Solutions, Orlando, FL

Kelley Butler, USAF, Tinker AFB, OK

Russell Campbell, Lockheed Martin Tactical Aircraft Systems, Ft. Worth, TX

Harry Carl, Honeywell, Minneapolis, MN

Jeffery Carter, NCR Corporation, San Diego, CA

Ranjan Chak, Oracle Software India Limited, Bangalore, India

Bhaskar Chavali, NIIT, New Delhi, India

Mary Beth Chrissis, The Software Engineering Institute, Pittsburgh, PA

Bill Curtis, TeraQuest Metrics, Inc., Austin, TX

Donna Dunaway, The Software Engineering Institute, Pittsburgh, PA

Kenneth Dymond, Process Transition International, Inc., Annapolis, MD

Suzanne Garcia, aimware Inc., Pittsburgh, PA

CMU/SEI-2000-SR-003 
Ellen George, AlliedSignal Aerospace Co., Teterboro, NJ

Kelly Gunning, Marconi Integrated Systems, San Diego, CA

Rick Hefner, TRW Inc., Redondo Beach, CA

Andre Heijstek, Ericsson, PN Gouda, Netherlands

Barbara Hirsh, Motorola Inc., Woodridge, IL

Watts Humphrey, The Software Engineering Institute, Pittsburgh, PA

Pankaj Jalote, I.I.T. Kanpuri, , India

Stephen Janiszewski, AlliedSignal Aerospace Co., Teterboro, NJ

Keith Joyce, Marconi Integrated Systems, San Diego, CA

Bijay Kumar Jyotishi, Wipro Technologies, Bangalore, India

Barbara Kolkhorst, IBM Global Services, College Station, TX

Anand Kumar, CitiCorp Information Technology Industries, Ltd., Mumbai, India

A Kumaran, Oracle Software India Limited, Bangalore, India

Walter Lipke, OC ALC, Tinker AFB, OK

Ray Madachy, Litton Guidance and Control Systems, Woodland Hills, CA

Steve Masters, CISE, Pittsburgh, PA

Andrew Meadow, PRC, Inc., McLean, VA

Judah Mogilensky, Process Enhancement Partners, Inc., Silver Spring, MD

Jane Moon, Raytheon, Fullerton, CA

Linda Morris, NCR, San Diego, CA

Mark Paulk, The Software Engineering Institute, Pittsburgh, PA

Mary Lynn Penn, Lockheed Martin, Philadelphia, PA 
William Peterson, The Software Engineering Institute, Pittsburgh, PA

Neil Potter, The Process Group, Dallas, TX

Joseph Puffer, TeraQuest Metrics, Inc., Austin, TX

Leitha Purcell, Northrop Grumman Corporation, Pico Rivera, CA

Lakshminarayanan Ravichandran, HCL Perot Systems, Noida, India

Sarala Ravishankar, Motorola India Electronics Ltd., Bangalore, India

Warren Schwomeyer, Lockheed Martin Federal Systems, Owego, NY

Michael Scott, Raytheon, Tucson, AZ

Joseph Seppy, Software Productivity Consortium, Herndon, VA

Prabhat Kumar Sinha, Satyam Computer Services Limited, Hyderabad, India

John Smith, Noumena Consulting Group, Inc., Beavercreek, OH

Rakesh Soni, HCL Perot Systems, Noida, India

Phillip Sperling, Telos Federal Systems, Lawton, OK

Prathima Srinath, IBM Global Services, North Plainfield, NJ

Agapi Svolou, Agapi Svolou, Independent Consultant, Pittsburgh, PA

Carolyn Swanson, Consultant, Plano, TX

M. Thangarajan, Tata Elxsi Limited, Bangalore, India

Barbara Tyson, The Software Engineering Institute, Arlington, VA

Subramanyam Venkata, Wipro Technologies, Bangalore, India

Ramesh Venkatraman, BFL Software Limited, Bangalore, India

Ramaswami Viswanathan, Wipro GE Medical Systems, Bangalore, India

Charles Weber, The Software Engineering Institute, Boulder, CO 
Donald White, Lockheed Martin Undersea Systems, Manassas, VA

Gary Wigle, The Boeing Company, Seattle, WA

David Zubrow, The Software Engineering Institute, Pittsburgh, PA 


\section{Appendix B: List of High Maturity Organizations Participating}

The following list of high maturity organizations lists most of the known Level 4 and 5 organizations. The organizations that participated in the workshop are noted with a $\sqrt{ }$ in column 1 of the table. A more comprehensive list, including points of contact, dates of assessment, and Lead Assessors is maintained at <URL: http://www.sei.cmu.edu/cmm/ cmm.articles.html \#high-mat-orgs $>$.

As of February 15, 2000, the full list, of which the published list is a subset, includes

- 44 Level 4 organizations

- 27 Level 5 organizations

- 26 non-US high maturity organizations

- 1 ML4 in Australia

- 14 ML4 in India

- 10 ML5 in India

- 1 ML4 in Israel

26 high maturity organizations participated in the workshop. Of the 26 , there were representatives from 12 companies in India.

Please be aware of the following issues regarding this list.

- The SEI does not certify companies at maturity levels.

- The SEI does not confirm the accuracy of the maturity levels reported by the Lead Assessors or organizations.

- This list of Level 4 and 5 organizations is by no means exhaustive; we know of other high maturity organizations that have chosen not to be listed.

- The SEI did not use information stored within its Process Appraisal Information System to produce this document.

- The organizations listed gave explicit permission to publish this information.

- No information obtained in confidence was used to produce this list.

\begin{tabular}{|l|l|}
\hline $\begin{array}{l}\text { Workshop } \\
\text { Participant }\end{array}$ & High Maturity Organization \\
\hline$\sqrt{ }$ & BFL Software Limited, Bangalore, India \\
\hline & $\begin{array}{l}\text { The Boeing Company, Aircraft \& Missiles \& Phantom Works Southern Califor- } \\
\text { nia, Long Beach, CA }\end{array}$ \\
\hline
\end{tabular}




\begin{tabular}{|c|c|}
\hline Workshop & High Maturity Organization \\
\hline & $\begin{array}{l}\text { The Boeing Company, Military Aircraft \& Missile Systems F/A-18 Mission } \\
\text { Computer, St. Louis, MO }\end{array}$ \\
\hline & $\begin{array}{l}\text { The Boeing Company, Reusable Space Systems and Satellite Programs, } \\
\text { Huntington Beach \& Seal Beach, CA }\end{array}$ \\
\hline \multirow[t]{2}{*}{$\sqrt{ }$} & $\begin{array}{l}\text { The Boeing Company, Space Transportation Systems, Kent, WA [Fowler 97, } \\
\text { Wigle 97, Yamamura 97] }\end{array}$ \\
\hline & CG-Smith Software, Bangalore, India \\
\hline \multirow[t]{4}{*}{$\sqrt{ }$} & Citicorp Information Technology Industries Limited (CITIL), Mumbai, India \\
\hline & Cognizant Technology Solutions, Chennai, India \\
\hline & DSQ Software, Chennai, India \\
\hline & Future Software Private Limited, Chennai, India \\
\hline \multirow[t]{2}{*}{$\sqrt{ }$} & HCL Perot Systems, Noida and Bangalore, India \\
\hline & $\begin{array}{l}\text { Honeywell International, Avionics Integrated Systems (formerly AlliedSignal, } \\
\text { Guidance \& Control Systems), Teterboro, NJ }\end{array}$ \\
\hline \multirow[t]{2}{*}{$\sqrt{ }$} & IBM Global Services India, Bangalore, India \\
\hline & International Computers India Ltd. (ICIL), Pune, India \\
\hline$\sqrt{ }$ & Litton Guidance and Control Systems, Woodland Hills, CA \\
\hline$\sqrt{ }$ & Lockheed Martin Federal Systems, Owego, NY \\
\hline$\sqrt{ }$ & Lockheed Martin Management \& Data Systems, King of Prussia, PA \\
\hline \multirow[t]{3}{*}{$\sqrt{ }$} & Lockheed Martin Mission Systems, Gaithersburg, MD \\
\hline & $\begin{array}{l}\text { Lockheed Martin Naval Electronics \& Surveillance Systems - Syracuse, Syra- } \\
\text { cuse, NY }\end{array}$ \\
\hline & $\begin{array}{l}\text { Lockheed Martin Naval Electronics \& Surveillance } \\
\text { Systems - Eagan, Eagan, MN }\end{array}$ \\
\hline \multirow[t]{4}{*}{$\sqrt{ }$} & $\begin{array}{l}\text { Lockheed Martin Naval Electronics \& Surveillance Systems - Manassas (for- } \\
\text { merly Undersea Systems), Manassas, VA }\end{array}$ \\
\hline & $\begin{array}{l}\text { Lockheed Martin Naval Electronics \& Surveillance Systems - Moorestown, } \\
\text { Moorestown, NJ }\end{array}$ \\
\hline & $\begin{array}{l}\text { Lockheed Martin Space Electronics and Communications Systems - Manassas } \\
\text { (formerly Loral Federal Systems), Manassas, VA }\end{array}$ \\
\hline & Motorola Australia Software Centre, Adelaide, Australia \\
\hline$\sqrt{ }$ & $\begin{array}{l}\text { Motorola, GSM (Global System for Mobile Communications) Systems Division, } \\
\text { Network Systems Group, Arlington Heights, IL [Miller 98] }\end{array}$ \\
\hline \multirow[t]{2}{*}{$\sqrt{ }$} & Motorola India Electronics Ltd. (MIEL), Bangalore, India [Ravishankar 99] \\
\hline & $\begin{array}{l}\text { NCR Corporation, Teradata Development Division, Massively Parallel Systems, } \\
\text { San Diego, CA }\end{array}$ \\
\hline \multirow[t]{2}{*}{$\sqrt{ }$} & $\begin{array}{l}\text { Northrop Grumman, Air Combat Systems, Integrated Systems and Aeronautics } \\
\text { Sector, El Segundo, CA }\end{array}$ \\
\hline & $\begin{array}{l}\text { Northrop Grumman, Integrated Systems \& Aerostructures, AEW \& EW Systems } \\
\text { (formerly Surveillance \& Battle Management), Bethpage, NY }\end{array}$ \\
\hline
\end{tabular}




\begin{tabular}{|l|l|}
\hline $\begin{array}{l}\text { Workshop } \\
\text { Participant }\end{array}$ & High Maturity Organization \\
\hline$\sqrt{ }$ & Oracle Software India Limited, India Development Center, Bangalore, India \\
\hline & Raytheon (formerly Raytheon E-Systems), Garland, TX \\
\hline$\sqrt{ }$ & $\begin{array}{l}\text { Raytheon C3I Fullerton Integrated Systems, Command and Control Sys- } \\
\text { tems/Middle East Operations, Fullerton, CA }\end{array}$ \\
\hline$\sqrt{ }$ & Raytheon Missile Systems, Software Engineering Center, Tucson, AZ \\
\hline$\sqrt{ }$ & Satyam Computer Services Ltd., India \\
\hline & Tata Consultancy Services, HP Centre, Chennai, India \\
\hline & Tata Consultancy Services, SEEPZ, Mumbai, India \\
\hline$\sqrt{ }$ & Tata Consultancy Services, Shollinganallur, Chennai, India \\
\hline & Tata Consultancy Services, US West, Chennai, India \\
\hline$\sqrt{ }$ & Tata Elxsi Limited, Bangalore, India \\
\hline$\sqrt{ }$ & Telcordia Technologies, Piscataway, NJ [Ferrara 00] \\
\hline$\sqrt{ }$ & $\begin{array}{l}\text { United Space Alliance, Space Shuttle Onboard Software Project, Houston, TX } \\
\text { [Billings 94, Fishman 97, Krasner 94, Paulk 95] }\end{array}$ \\
\hline$\sqrt{ }$ & $\begin{array}{l}\text { US Air Force, Ogden Air Logistics Center, Technology \& Industrial Support } \\
\text { Directorate, Software Engineering Division, Hill AFB, UT [Cosgriff 99a, Cos- } \\
\text { griff 99b, Craig 99, Oldham 99, Paulk 99] }\end{array}$ \\
\hline$\sqrt{ }$ & $\begin{array}{l}\text { US Air Force, Oklahoma City Air Logistics Center, Directorate of Aircraft Man- } \\
\text { agement, Software Division, Test Software and Industrial Automation Branches } \\
\text { (OC-ALC/LAS), Tinker AFB, OK [Butler 95, Butler 97] }\end{array}$ \\
\hline $\begin{array}{l}\text { US Army, Communications and Electronics Command (CECOM), (Software } \\
\text { Engineering Center (SEC), Fire Support Software Engineering, Fort Sill, OK }\end{array}$ \\
\hline US Navy, Fleet Material Support Office, Mechanicsburg, PA \\
\hline Wipro GE Medical Systems, Bangalore, India \\
\hline Wipro Technologies, Enterprise Solutions Division, Bangalore, India \\
\hline $\begin{array}{l}\text { Wipro Technologies, Global R \& D (formerly Technology Solutions), Bangalore, } \\
\text { India }\end{array}$ \\
\hline
\end{tabular}




\section{Appendix C: SEI Strategy for Ensuring Valid Implementation and Appraisal of Level 4 and 5 Process Areas: October 28, 1999}

\section{Introduction and Background}

When the Capability Maturity Model $\left(\mathrm{CMM}^{\circledR}\right)$ for Software (SW-CMM) was initially published by the Software Engineering Institute (SEI), comparatively little was known about the practices of organizations at levels 4 and 5. Although conceptually it was understood what levels 4 and 5 should look like, real examples of these types of organizations were scarce in the software community. The concepts for the level 4 and 5 key process areas were based on ideas of some of the leading thinkers in the software community. The goals and practices for the key process areas were adapted from other non-software industries. These goals and practices were tailored to what was believed to be reasonable for a software process.

While initially proposed level 4 practices were based on statistical quality control (SW-CMM V1.0), the current SW-CMM V1.1 emphasizes quantitative management and quantitative control. This more accurately reflected the state-of-the-practice in software engineering at the time. Over the last few years, the mature software organizations have used rigorous statistics and statistical process control (SPC) techniques in their implementation of maturity levels 4 and 5. Based on these observations and other sources, the level 4 and 5 key process areas of SWCMM V2.0 draft $\mathrm{C}$ were focused toward the use of rigorous statistical methods. The reviewers of the drafts of SW-CMM V2.0 generally supported this approach. CMMI models are to a large degree adopting the level 4 and 5 key process areas from SW-CMM V2.0 draft C.

As the number of organizations assessed at levels 4 and 5 has grown over the last few years, there is a concern that there is a wide range of interpretations of the level 4 and 5 key process areas. There may be interpretations that are inconsistent with what was intended by the goals and practices of these key process areas. This potential has become a serious concern to many users of the SW-CMM. As more and more maturity level 4 and 5 appraisals occur and are described in papers and presentations, the essential requirements for achieving level 4 or level 5

Capability Maturity Model and CMM are registered in the U.S. Patent and Trademark Office. 
may be eroding. While there are likely to be differences of interpretation over a process model such as the SW-CMM, a common understanding must be developed in the software community as to what constitutes an acceptable approach to maturity levels 4 and 5, including both the deployment and institutionalization. If this potential erosion is not stopped and reversed, the usefulness of the SW-CMM, as well as other CMMs, will be in serious jjeopardy.

\section{Purpose}

The purpose in establishing this strategy is to define specific actions that the SEI and others in the software community can implement so that users of the SW-CMM V1.1 and other capability maturity models have a clear and common understanding of what needs to be done to implement maturity levels 4 and 5. In this regard, we need to address the needs of (1) process improvement practitioners, (2) process appraisal teams, and (3) management of the organizations that are the recipients of the process improvement and appraisals. With regard to the appraisal teams, we also need to define actions to ensure that the appraisals of the maturity level 4 and 5 key process areas are valid and consistent across appraisal teams.

\section{Candidate Strategies for Addressing the Need}

In addressing the concern of inconsistent and inappropriate interpretation of the level 4 and 5 key process areas, our strategy needs to approach the problem from multiple directions.

- It has to address both honest misunderstanding as well as any intentional misapplication.

- It has to undo some of the damage already caused as well as prevent future erosion.

- It has to provide support for organizations to achieve satisfaction against SW-CMM V1.1 as well as support organizations that want to continue to evolve beyond SW-CMM V1.1.

- It has to start by gaining a common understanding and approach within the SEI and then transition these ideas into the rest of the CMM community.

The following is a list of candidate actions that can be taken, as well as actions completed or underway. The completed and underway actions are included for completeness and to ensure that they are considered in the overall strategy.

\section{Internal SEI Actions ${ }^{3}$}

a. Establish and maintain the plan for implementing this strategy to address the problem of inconsistent and inappropriate interpretation of the level 4 and 5 key process areas.

b. Define the steps that will be taken to ensure consistency and validity in appraisals of high maturity organizations.

c. Develop SEI level 4 and 5 qualified individuals to represent SEI in level 4 and 5 discussions, training, consultation, and appraisals.

\footnotetext{
${ }^{3}$ These internal actions are intended to support or provide the basis for external actions.
} 


\section{Define Improvements for Maturity Level 4 and 5 Process Areas and Appraisals of SW-CMM V1.1 and other CMMs.}

a. Establish clear criteria for determining satisfaction of the level 4 and 5 key process areas.

b. Define heuristics for appraising an organization against the level 4 and 5 key process areas.

c. Develop guidance for crafting process improvement recommendations to enable organizations to achieve level 4 and 5.

d. Develop guidance for crafting process improvement recommendations for organizations that achieved level 4 and 5 and want to improve beyond SW-CMM V1.1 and other CMMs.

\section{CMM Training and Education}

a. Offer the "Software Engineering and Management Practices of High Maturity Organizations". Scheduled dates: February 8-10, June 20-22, October 3-5, 2000.

b. Offer the "Statistical Process Control for Software". Scheduled dates: February 1-3, May 2-4, October 10-12, 2000.

c. Develop and offer Intermediate Model Training for potential Lead Assessors and SEPG persons who need more in-depth knowledge of the CMM than provided in the "Intro" course, including more robust treatment of process areas and real-world examples of practices at each maturity level.

\section{Appraisal Method Training and Education}

a. Upgrade the "CBA Lead Assessor" course for more emphasis on high maturity practices.

b. Upgrade the "SCE Lead Evaluator" course for more emphasis on high maturity practices.

c. Require Intermediate Model Training for experienced Lead Assessors and Lead Evaluators.

d. Provide training for existing Lead Assessors and Lead Evaluators on High Maturity Practices.

\section{Workshops}

a. Conduct CMM High Maturity Practices workshops. Scheduled for November 16-18, 1999.

\section{Conference and Journal Papers}

a. Provide qualified referees to conference program committees and journal editorial boards to review papers dealing with level 4 and 5 issues.

b. Publish and present a paper: "Building and Assessing High Maturity Organizations" 


\section{Technical Reports and Publications}

a. "Practical Software Measurement: Measuring for Process Management and Improvement" handbook: CMU/SEI-97-HB-003.

b. "Statistical Process Control for Software" by William Florac and Anita Carleton, published by Addison Wesley, 1999.

\section{Informal Communications Between the SEI and the} CMM Community

a. Publish white papers on CMM interpretation and appraisal issues

b. Publish questions and answers on SW-CMM interpretation and appraisal issues

c. Use the Lead Assessor Web Center as a forum for discussion of these issues and review comments on papers. 


\begin{tabular}{|c|c|c|c|c|}
\hline RE & PORT DOC & ITATION PAGE & & $\begin{array}{l}\text { Form Approved } \\
\text { OMB No. 0704-0188 }\end{array}$ \\
\hline $\begin{array}{l}\text { Public r } \\
\text { existing } \\
\text { burden } \\
\text { Director } \\
\text { and Bus }\end{array}$ & $\begin{array}{l}\text { eporting burden for this cc } \\
\text { data sources, gathering } \\
\text { estimate or any other asp } \\
\text { rate for information Opera } \\
\text { dget, Paperwork Reductio }\end{array}$ & $\begin{array}{l}\text { nation is estimated to average } 1 \text { hour } p e \\
\text { the data needed, and completing and re } \\
\text { tion of information, including suggestion } \\
\text { s, } 1215 \text { Jefferson Davis Highway, Suite } \\
\text { o188), Washington, DC 20503. }\end{array}$ & $\begin{array}{l}\text { se, includ } \\
\text { he collect } \\
\text { ucing this } \\
\text { lington, }\end{array}$ & $\begin{array}{l}\text { ding the time for reviewing instructions, searching } \\
\text { tion of information. Send comments regarding this } \\
\text { burden, to Washington Headquarters Services } \\
\text { VA 22202-4302, and to the Office of Management }\end{array}$ \\
\hline 1. & $\begin{array}{l}\text { AGENCY USE ONLY } \\
\text { (LEAVE BLANK) }\end{array}$ & $\begin{array}{l}\text { 2. REPORT DATE } \\
\text { March } 2000\end{array}$ & 3. & $\begin{array}{l}\text { REPORT TYPE AND DATES COVERED } \\
\text { Final }\end{array}$ \\
\hline 4. & $\begin{array}{l}\text { TITLE AND SUBTITLE } \\
\text { The November }\end{array}$ & h Maturity Workshop & 5. & $\begin{array}{l}\text { FUNDING NUMBERS } \\
C-F 19628-95-C-0003\end{array}$ \\
\hline 6. & $\begin{array}{l}\text { AUTHOR(s) } \\
\text { Mark C. Paulk, }\end{array}$ & Chrissis & & \\
\hline 7. & $\begin{array}{l}\text { PERFORMING ORGA } \\
\text { Software Engin } \\
\text { Carnegie Mello } \\
\text { Pittsburgh, PA }\end{array}$ & $\begin{array}{l}\text { ME(S) AND ADDRESS(ES) } \\
\text { titute } \\
\text { ity }\end{array}$ & 8. & $\begin{array}{l}\text { PERFORMING ORGANIZATION } \\
\text { REPORT NUMBER } \\
\text { CMU/SEI-2000-SR-003 }\end{array}$ \\
\hline 9. & $\begin{array}{l}\text { SPONSORING/MONIT } \\
\text { HQ ESC/XPK } \\
5 \text { Eglin Street } \\
\text { Hanscom AFB, }\end{array}$ & $\begin{array}{l}\text { CY NAME(S) AND ADDRESS(ES) } \\
1-2116\end{array}$ & & $\begin{array}{l}\text { SPONSORING/MONITORING } \\
\text { AGENCY REPORT NUMBER }\end{array}$ \\
\hline 11. & SUPPLEMENTARY NC & & & \\
\hline 12.A & $\begin{array}{l}\text { DISTRIBUTION/AVAIL } \\
\text { Unclassified/Ur }\end{array}$ & $\begin{array}{l}\text { TEMENT } \\
\text { TIC, NTIS }\end{array}$ & 12.B & DISTRIBUTION CODE \\
\hline
\end{tabular}

13. ABSTRACT (MAXIMUM 200 WORDS)

A workshop for high maturity organizations was held on November 16-18, 1999, at the Software Engineering Institute (SEI) in Pittsburgh. The purpose of this workshop was to better understand practices that characterize Level 4 and 5 organizations. Topics of discussion included both practices described in the CMM and other practices that have a significant impact in mature organizations. Two themes were anticipated to be important to the workshop participants: statistical process control for software and the reliability and credibility of Level 4 and 5 assessments. Additional topics were solicited from the participants on CMM integration, measurement, technology, human issues, and quality assurance. This report contains brief summaries of the high maturity organizations participating in the workshop and the various working group reports.

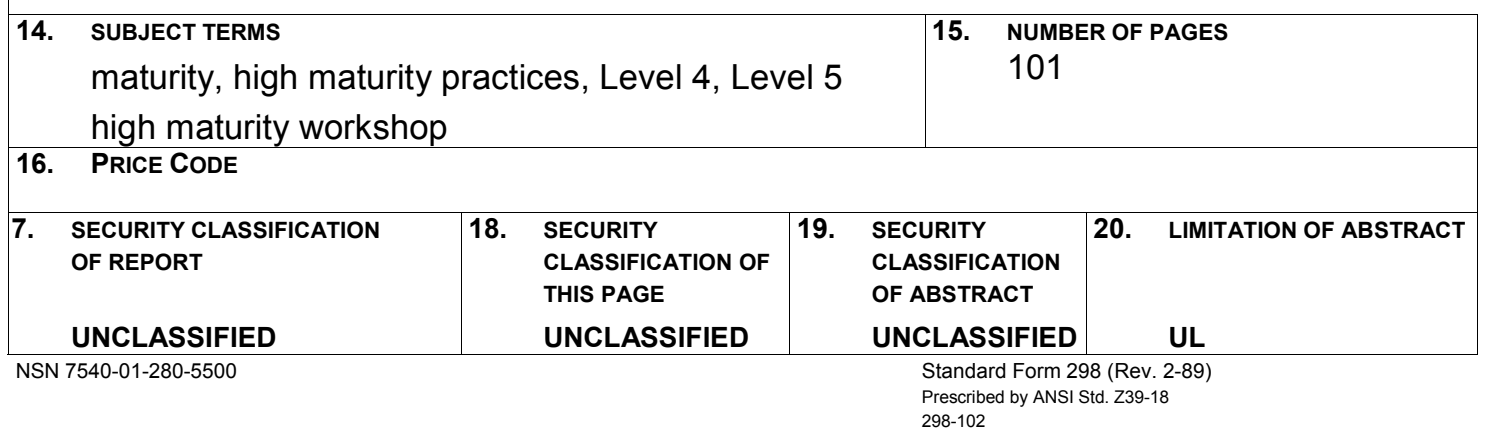

